Article

\title{
Detecting Large-Scale Landslides Using Lidar Data and Aerial Photos in the Namasha-Liuoguey Area, Taiwan
}

\author{
Meei-Ling Lin ${ }^{1}{ }^{\text {, }}$, Te-Wei Chen ${ }^{1}$, Ching-Weei Lin ${ }^{2}$, Dia-Jie Ho ${ }^{2}$, Keng-Ping Cheng ${ }^{3}$, \\ Hsiao-Yuan Yin $^{3}$ and Mei-Chen Chen ${ }^{3}$
}

1 Department of Civil Engineering, National Taiwan University, No. 1, Sec. 4, Rooservelt Road, Taipei 10617, Taiwan; E-Mail: acura0308@gmail.com

2 Department of Earth Science, National Cheng Kung University, No.1, University Road, Tainan 701, Taiwan; E-Mails: chingwee@mail.ncku.edu.tw (C.L.); chingwee@mail.ncku.edu.tw (D.H.)

3 Soil and Water Conservation Bureau, Council of Agriculture, Nantou 54044, Taiwan; E-Mails: ckp0119@mail.swcb.gov.tw (K.C.); sammya@mail.swcb.gov.tw (H.Y.); ckp0119@mail.swcb.gov.tw (M.C.)

* Author to whom correspondence should be addressed; E-Mail: linml@ntu.edu.tw; Tel.: +886-02-3366-4321; Fax: +886-02-2365-6281.

Received: 30 October 2013; in revised form: 21 November 2013 / Accepted: 9 December 2013 / Published: 19 December 2013

\begin{abstract}
Large-scale landslides often cause severe damage to lives and properties; therefore, their identification is essential in order to adopt proper mitigation measures. The objective of this study was to set up a methodological approach to help identify large-scale landslides using Lidar data, aerial photos and field investigation. The selected study areas were the Namasha and Liuoguey Areas in Kaohsiung City, Taiwan, both of which were severely hit by the Typhoon Morakot in 2009. The identification of large-scale landslides was performed based on Lidar high-resolution topographic information. The linear structures were mapped according to the shading map, with aspect in different azimuth to show good details of the structures. The scarps of the landslides were also identified. Validation of the results was done using both aerial photos and field investigations. In addition, stability analyses were performed on designated cases to further validate the results of Lidar identification.
\end{abstract}

Keywords: large-scale landslide; Lidar technique; shading map; scarps; stability analysis 


\section{Introduction}

Due to the fragile geologic structures and steep terrains, the heavy rainfall carried by typhoons often causes landslide and debris flow in Taiwan. In 2009, Typhoon Morakot struck Southern Taiwan, dumping more than $3,000 \mathrm{~mm}$ of accumulated rainfall on to the land. The large-scale landslide (landslide area larger than $10 \mathrm{ha}$ ) that occurred in the Shiaolin Area (Figure 1 [1,2]) affected an area of more than 270 ha and resulted in approximately 500 casualties. The landslide also caused the damming of the Chishan River, and the consequent flooding of the upward valley. Similarly, other large-scale landslides were observed in both the Chishan and the Laonong River watersheds. These landslides that occurred upstream of the debris flow torrents often contributed to debris transport, thereby increasing debris flow, and causing severe hazards and secondary hazards such as landslide dam and dam burst, or further debris transportation in subsequent rainfall events. An example of a large-scale landslide near the Tai-27Jia Highway next to the Laonong River is shown in Figure 2, where its head scarp can be easily identified. Thus, investigation and identification of potential large-scale landslides is crucial for hazard reduction.

Figure 1. The Shiaolin landslide in Chishan River watershed, Kaohsiung City, triggered by Typhoon Morakot.

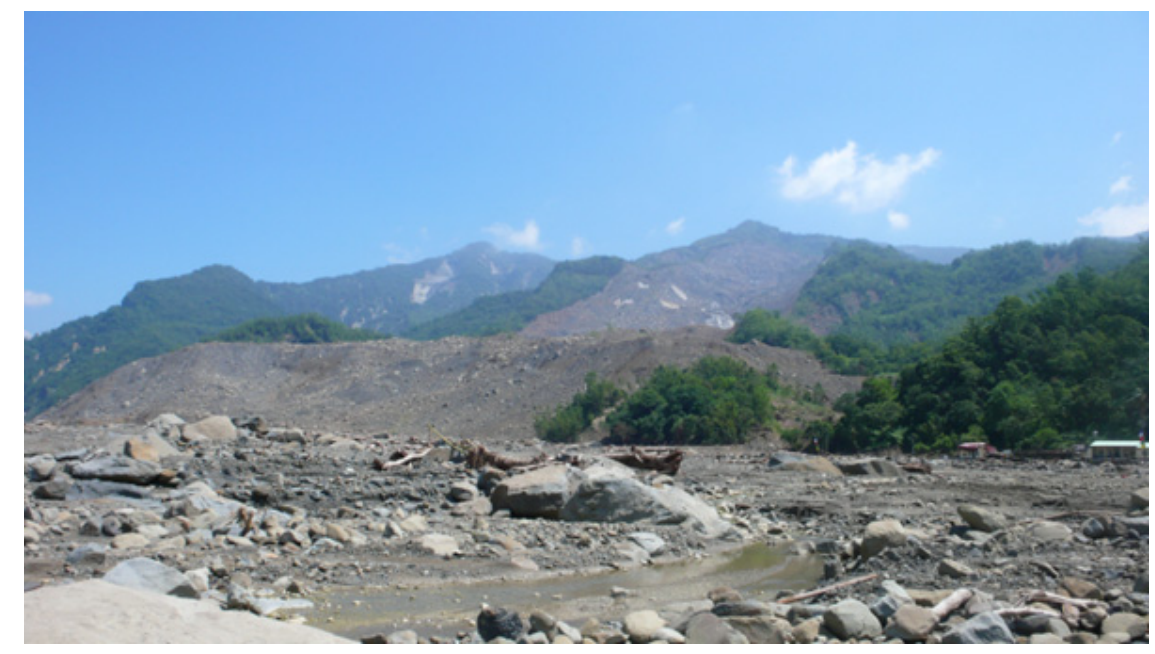

Remote sensing techniques have developed rapidly in recent years, with Lidar (Light Detecting And Ranging) high resolution DEM being utilized for engineering, hazard management, forestry, and farming purposes. The usage of Lidar technology in landslide identification has become increasingly popular. The radar wave can penetrate tree coverage to obtain ground elevation, and thus can provide more details of the micro-topography of the area being studied. Schulz [3] and Schulz [4] used the Lidar DEM to identify the micro-topography of the Puget Sound region of Seattle. He found the Lidar data to be useful in identifying the complex large-scale landslide, and for locating potential landslides in the area as well. Schulz [3] used Lidar DEM with $2 \mathrm{~m}$ resolution to produce the slope and shading maps with aspect in $45^{\circ}, 135^{\circ}$, and $315^{\circ}$ azimuth angles, respectively, to identify the landslide. Different aspect shading maps were compared until the best aspect for identifying the potential landslide was found. Similarly, Miner et al. [5] used Lidar DEM to interpret the old landslides and 
potential landslides in the Victoria Otway Ranges near the Johanna area. They successfully used Lidar to separate the vegetation from the real ground elevation, and shading maps with different aspects to verify the landslide detection.

Figure 2. The large-scale landslide beside the Laonong River, Kaohsiung City, triggered by Typhoon Morakot.

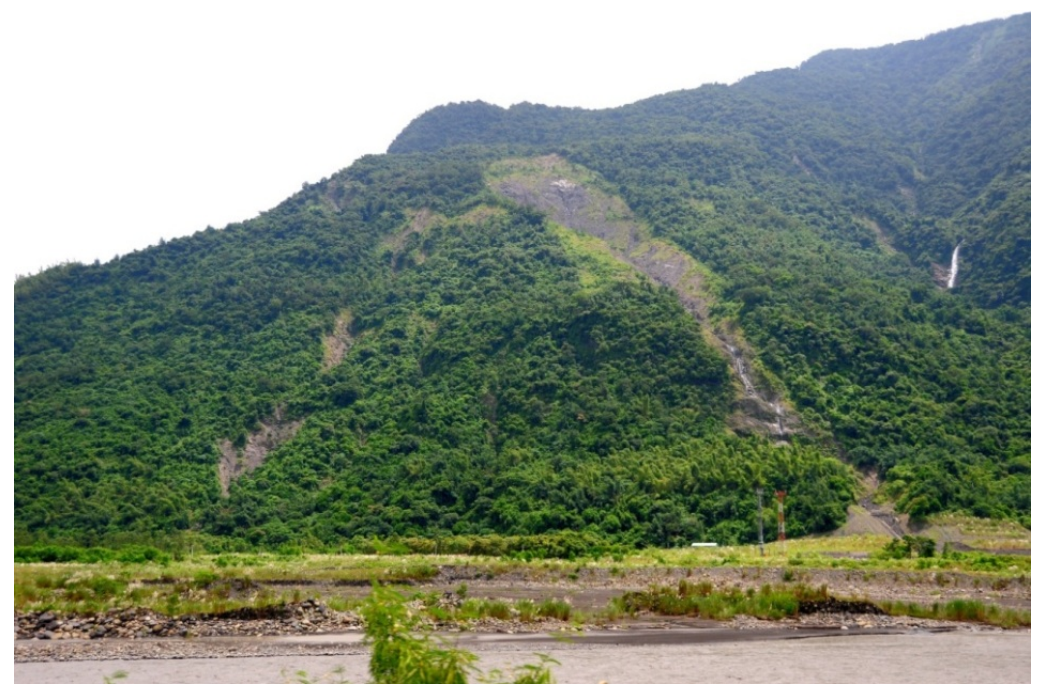

\section{Study Area}

Typhoon Morakot brought more than 2,000 $\mathrm{mm}$ of rainfall to the river valleys of Kaohsiung City in southern Taiwan, triggering landslides and debris flows to occur especially in the Namasha and Liuoguey areas. These landslides caused tremendous damage to roads, bridges, and properties, and resulted in the loss of many human lives. In addition, a significant number of large-scale landslides and debris flows related to the increase of loose debris were also observed in both areas. Large-scale landslides were induced by Typhoon Morakot in the up-stream area of debris flow torrent Kaohsiung Debris Flow No.007 (KSDF007) in the Namasha area, causing the debris to block the stream, leading to a dam failure and subsequent significant damage to the Nansalu Village [6] as shown in Figure 3. The aerial photo of the debris flow torrent KSDF007 and up-stream area is shown in Figure 4. In the figure, two large-scale landslides and several smaller landslides are also visible in the up-stream area. Several similar events occurred in the Namasha and Liuoguey areas. Further debris flows caused damage and difficulties in reconstruction in the area after Typhoon Morakot. Thus, the Namasha and Liuoguey areas in Kaohsiung City were selected as study areas where Lidar data would be used to identify large-scale landslides.

The geographic location and digital topographic map of the Namasha and Liuoguey areas are illustrated in Figure 5. In the figure, the northwest part represents the Namasha area and the southeast part represents the Liuoguey area, both of which are located in Kaohsiung City. 
Figure 3. Damage of an elementary school (left) and a resident's home (right) caused by debris flow affecting torrent KSDF007 in Nansalu Village, Kaohsiung City.

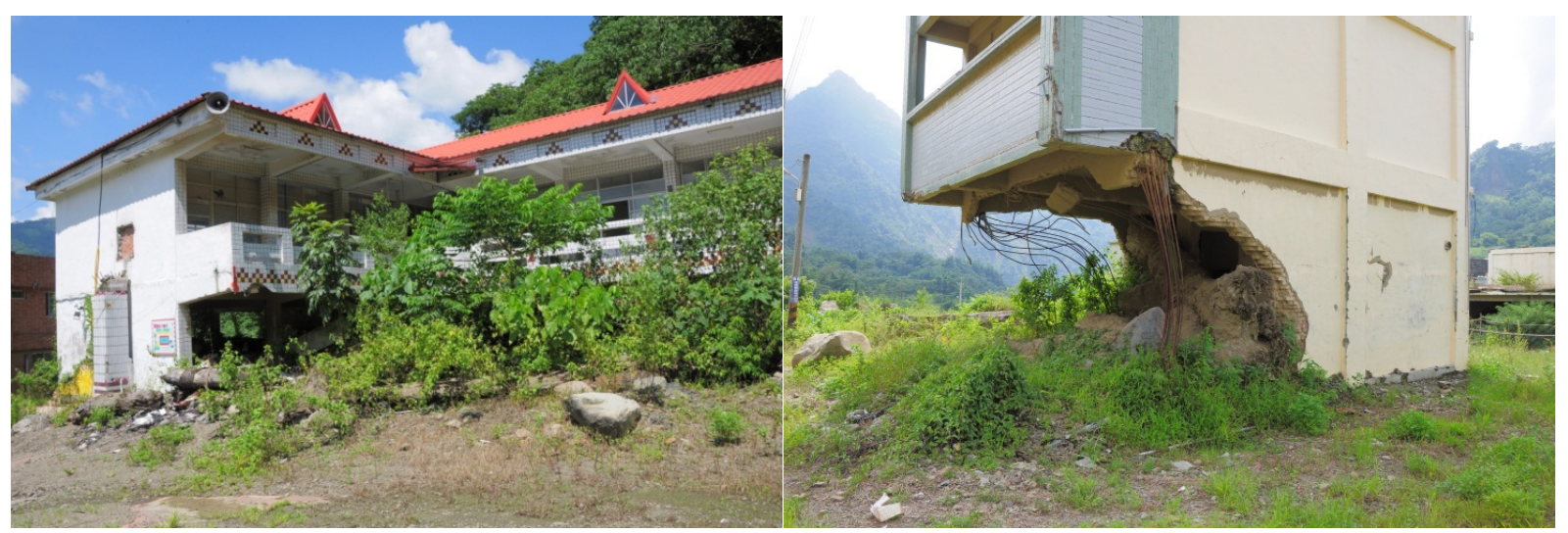

Figure 4. An aerial photo of the debris flow torrent KSDF007 taken after Typhoon Morakot. The debris deposition fan and landslides in the basin can be observed.

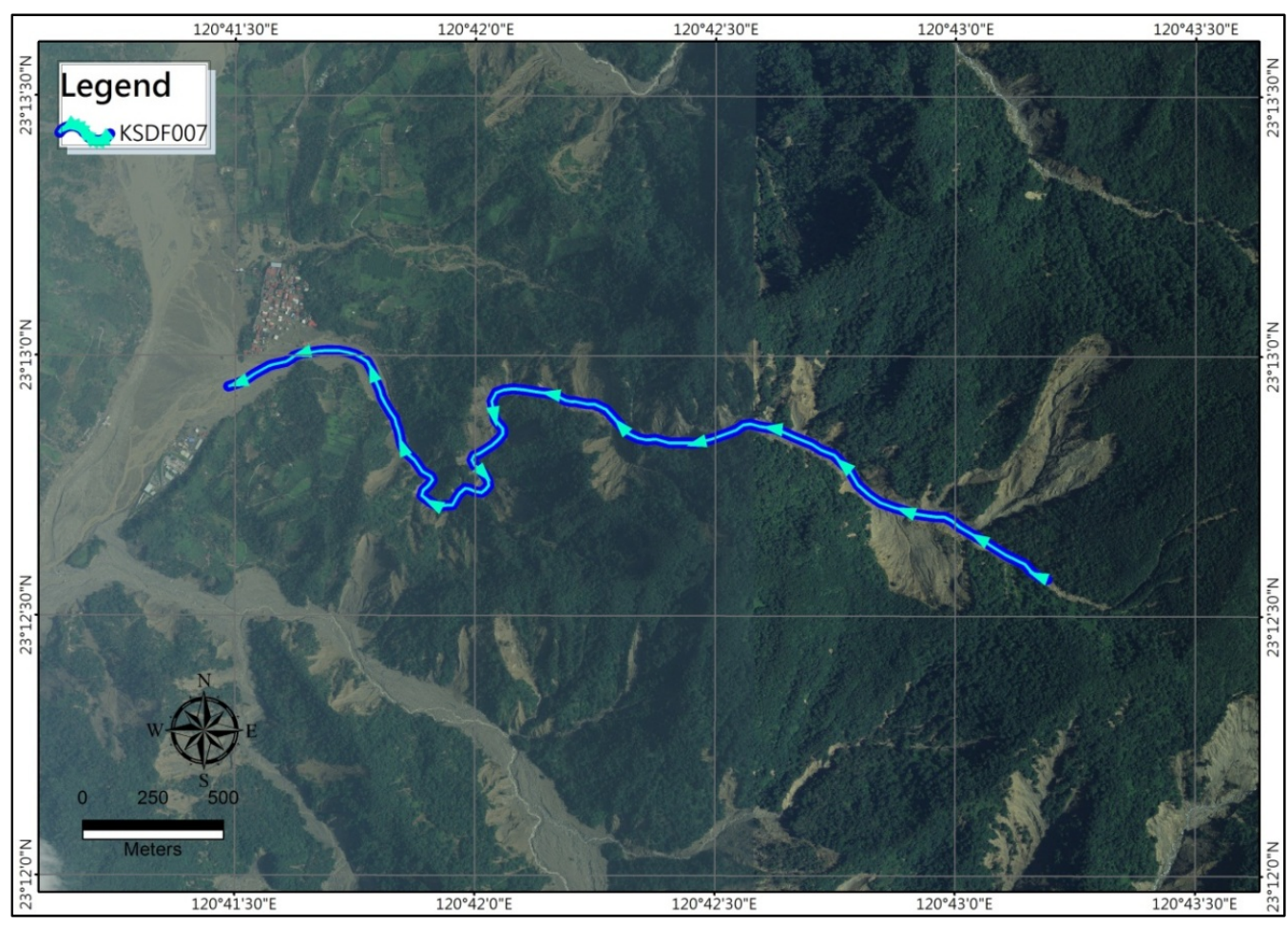

The geological map of the two areas is illustrated in Figure $6([7,8])$. The Namasha research area is in the Western Foothills Zone according to engineering geology classification in Taiwan, which is mainly composed of un-metamorphic rock of the Miocene with sandstone, siltstone, shale, and sandstone/shale interlayer formations. The engineering geology classification of the Liuoguey research area is located in the Central Mountain Range Zone, and the stratum is meta-argillite and meta-shale of the Tertiary epoch with mostly slate formations [9]. 
Figure 5. Location of the study area: the northwest part represents the Namasha area and the southeast part represents the Liuoguey area.

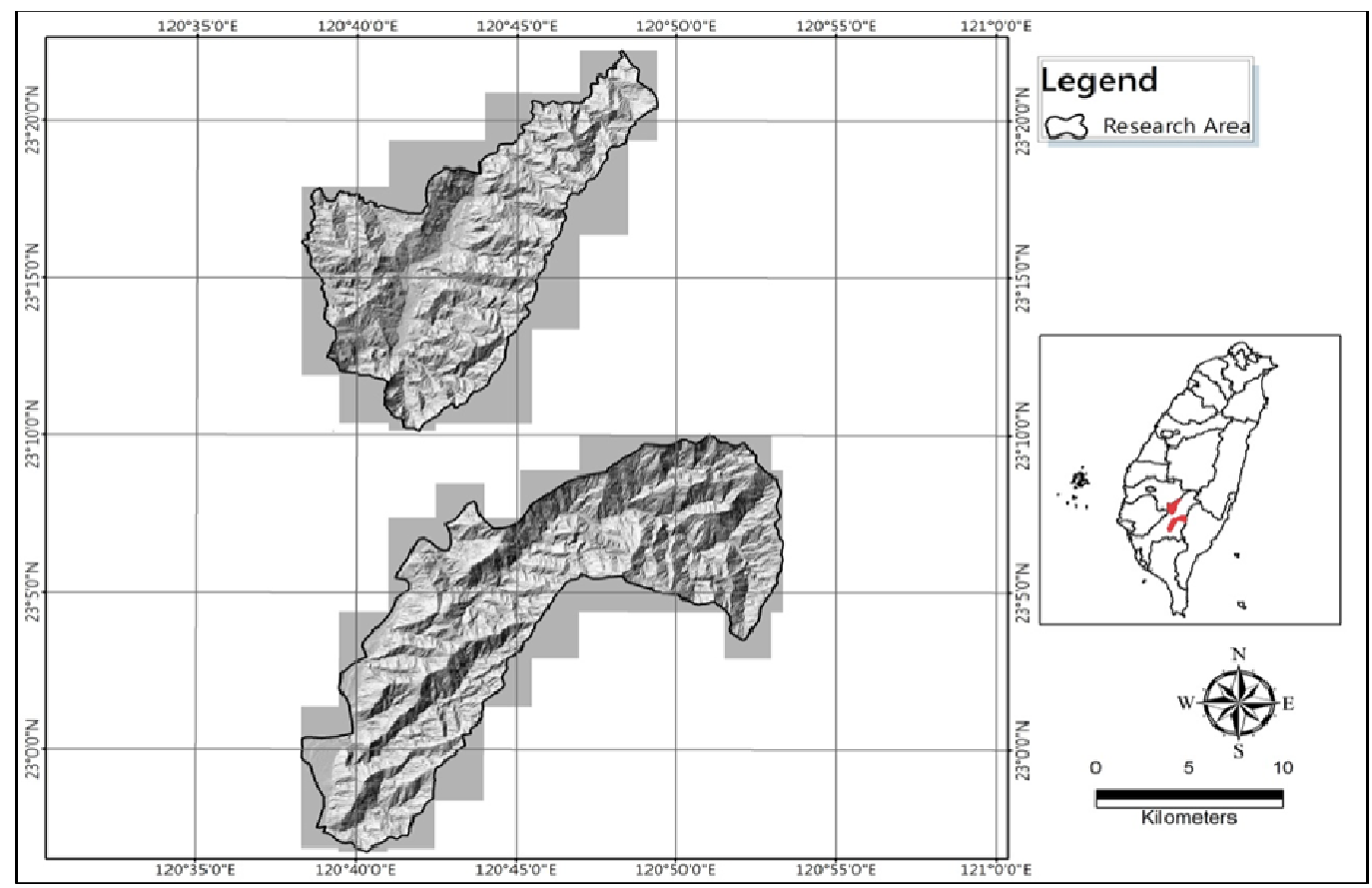

Figure 6. A geological map of the study area: the northwest part represents the Namasha area with mostly sedimentary rock formations, and the southeast part represents the Liuoguey area with mostly metamorphic rock formations.

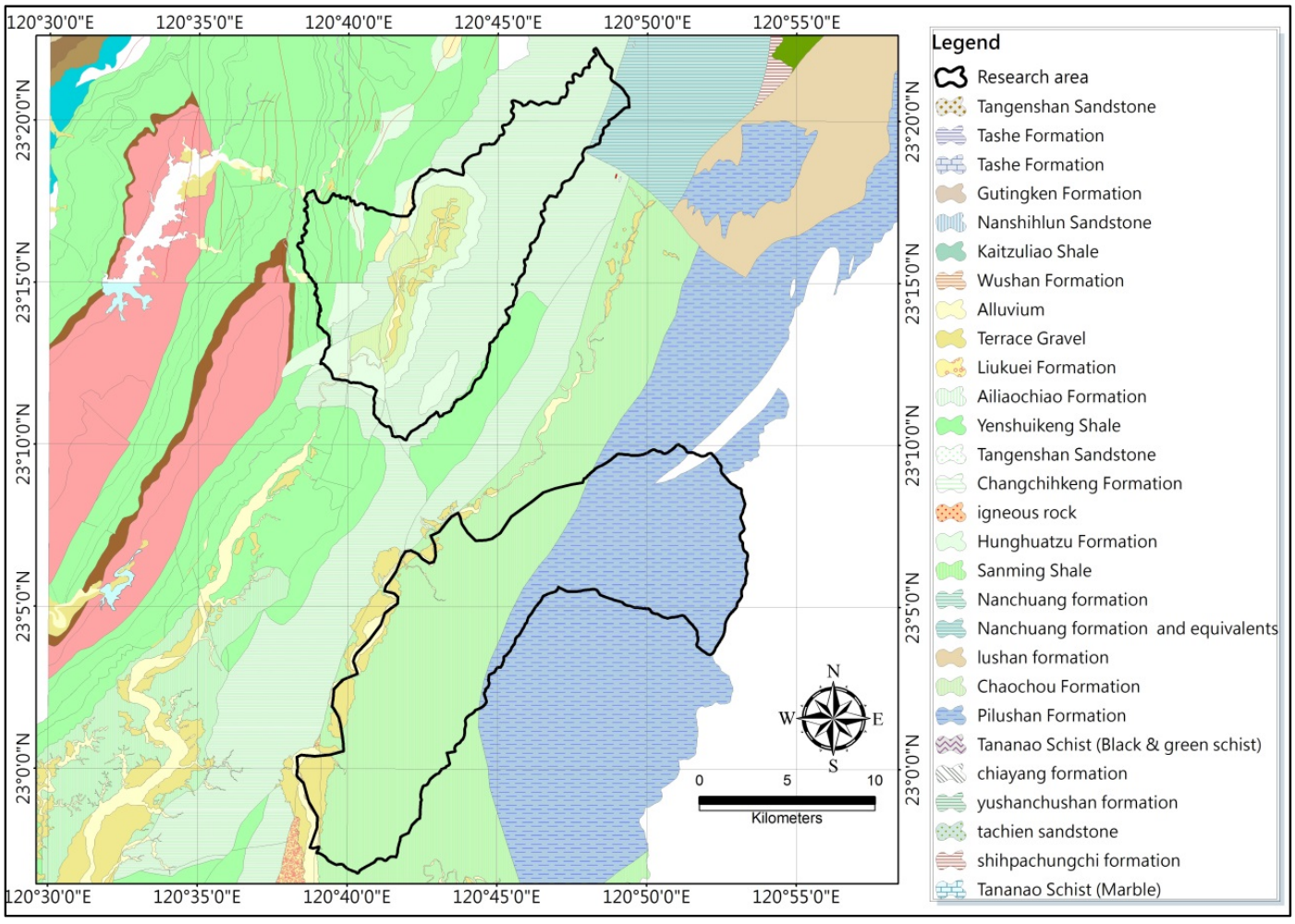




\section{Large-Scale Landslide Detection Using Lidar Data}

\subsection{Classification of Large-Scale Landslides}

The identification of large-scale landslides usually requires field investigation to better understand their characteristics. However, it is inefficient and uneconomic if regional investigation is required for government agency. On the other hand, the rapid development of Lidar technique and availability of high resolution digital elevation model data is providing greater detail of topographic variations which is very helpful in landslide detection. The detection of large-scale landslides is mainly based on identification of the geomorphologic features as proposed by Varnes [10] and Varnes [11]. These geomorphologic characteristics can be listed as follow: (1) crown with tension cracks, (2) main scarp head scarp, (3) related slide blocks, (4) minor scarp, (5) main body, (6) transverse tension cracks, and (7) toe bulge or swelling area as illustrated in Figure 7. Most of these features can be identified from aerial photos; however, differences in elevation of scarps or tension cracks that are not well exposed are difficult to pinpoint. In this case, Lidar data can be useful in reconstructing detailed topography of the ground.

Figure 7. The geomorphologic characteristics of large-scale landslide (modified from Varnes [10]).

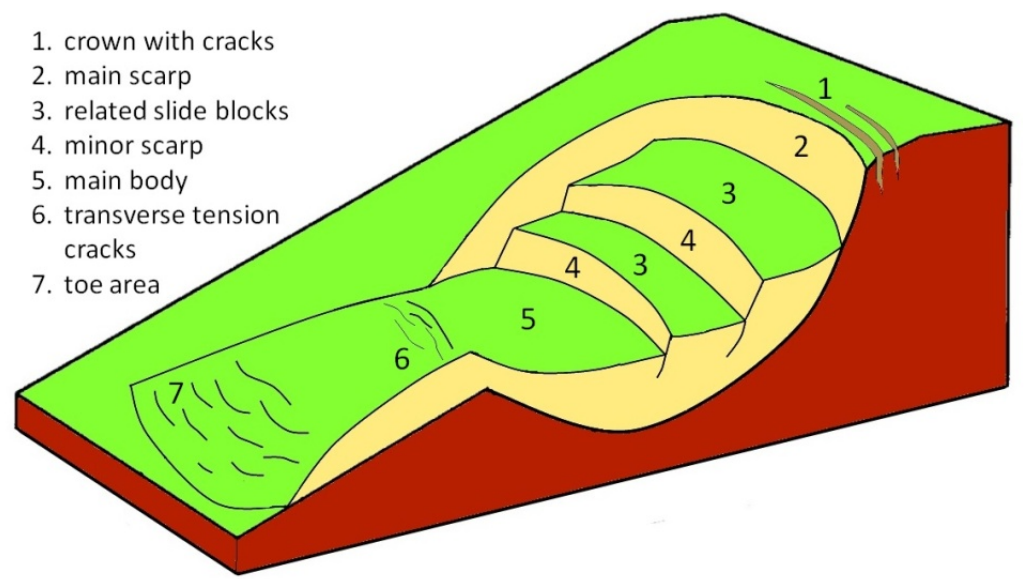

A landslide area of 10 ha (estimated based on Chigira [1]) is considered as the threshold for large-scale landslide mapping. Using Lidar DEM, satellite images, and aerial photos of the study area, the potential large-scale landslide areas in the torrent basin were identified based on the topographic characteristics, typically main scarps, and cracks at the toe of the slope. The large-scale landslides were then classified into four types as listed in Table 1, with an example illustrated in Figure 8.

Type A landslide is the newly occurred landslide, or current event, displaying significant geomorphologic evidences, clear scarps, and usually exposed bare land. Since the type A landslide has already occurred, if not much residual sliding mass remains on the slope, then the landslide will be less likely to recur in the near future. Figure $8 \mathrm{a}$ is an example of type A landslide in the tributary of the Baolai River in Liuoguey area. Type B is the landslide that previously occurred, or prior event, showing clear geomorphologic evidences, but with no significant scarps. The type B landslide had some vegetation recovery differing from its surrounding area, which suggested a period of within a 
decade. Figure $8 \mathrm{~b}$ is an example of type $\mathrm{B}$ in the Taoyuan District of Liuoguey area, noted the differences in vegetation of landslide area and neighbouring area. Type $\mathrm{C}$ is landslide with geomorphologic evidences and no clear signs of reactivation. This type is usually identified with geomorphologic features, including scars, side cracks, and linear structures near the crown, etc. Figure $8 \mathrm{c}$ is an example of type $\mathrm{C}$ in the Taoyuan District of Liuoguey area with features of some scars, erosion gullies, and swelling toe. Finally, type D is an area without geomorphologic evidence, but with geological settings like dip slope, joint and altitude suggesting the possible presence of a landslide. The type $\mathrm{D}$ is usually mapped according to correlation of the geological setting with respect to the topography of the slope, and is not discussed in this study.

Table 1. Classifications of large-scale landslide.

\begin{tabular}{cccc}
\hline Type & Classification & Landslide Occurrence & Properties \\
\hline A & Current event & Landslide & With clear geomorphologic evidences \\
and significant scarps
\end{tabular}

Figure 8. Illustration of type (a) A, (b) B and (c) C large-scale landslides from left to right, respectively.

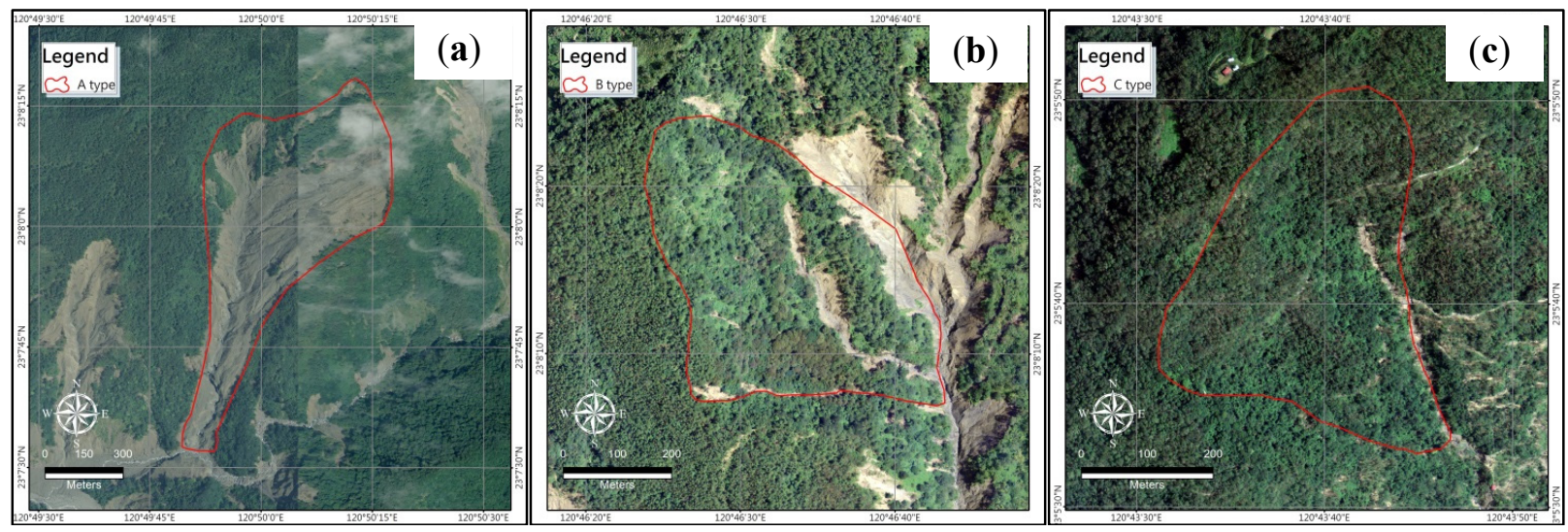

\subsection{The Resolution of Lidar DEM Data}

The digital elevation model represents topographic relief and ground elevation. A Lidar survey with the resolution of $2 \mathrm{~m} \times 2 \mathrm{~m}$ was carried out in the study area after Typhoon Morakot occurred by the Soil and Water Conservation Bureau (SWCB) in 2010 with the average point cloud density of $2 / \mathrm{m}^{2}$ in plane area and $0.5 / \mathrm{m}^{2}$ in the mountain area. The $2 \mathrm{~m} \times 2 \mathrm{~m}$ DEM was used to detect the geomorphologic features of large-scale landslides, including scarps, scars, cracks, and other related linear structures. Different resolution DEMs have been compared as shown in Figure 9. The $5 \mathrm{~m}$ resolution DEM of the downstream area of Nachilan River is shown in Figure 9a, and the $2 \mathrm{~m}$ resolution DEM of the same area is shown in Figure 9b. Since the high resolution DEM is more 
helpful in locating the topographic features, such as the linear structures, the $2 \mathrm{~m}$ resolution Lidar data produced by the SWCB were used in this study.

Figure 9. Comparisons of shading maps of (a) $5 \mathrm{~m}$ resolution DEM, and (b) $2 \mathrm{~m}$ resolution Lidar DEM, of the downstream area of Nachilan River, Namasha study area.

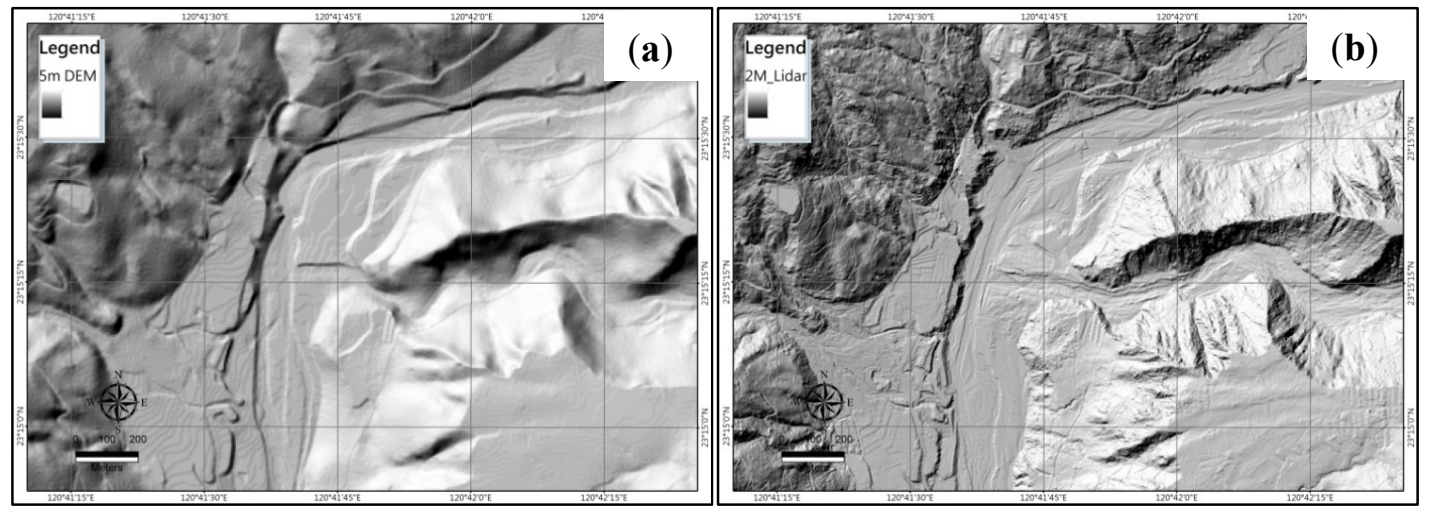

\subsection{Detection of Large-Scale Landslides}

The methodology adopted in identifying large-scale landslides is based on the location of the geomorphologic characteristics and significant scarps according to Varnes classifications [10,11]. The aerial photo (resolution of $25 \mathrm{~cm}$ ) is useful for finding exposed landslide scars, but is not very effective in identifying linear structures such as cracks. However, good resolution Lidar data can provide enough details to identify linear structures. The shading maps of KSDF007 debris flow torrent area derived from $2 \mathrm{~m}$ resolution Lidar data in eight different aspects were used to find the cracks and scarps as illustrated in Figure 10 [12]. The red lines mark the scars (linear structures) in the landslide area. The different aspect shading maps provide different distinctive information, and the one providing the most significant linear structures has been used to locate the landslide features. The results are shown in Figure 11. Figure 11a shows the original Lidar shading map, and in Figure 11b the identification results are plotted in shading map of the best aspect angle.

With the mapped linear structures, the large-scale landslide was identified by detecting the morphological evidences described below:

(1)Crown: the top of the large-scale landslide with tension cracks.

(2)Scarp: the scars form an approximate horseshoe shape; newly developed scars are brighter, circular tension cracks are found on top of the scars, swamps and/or ponds usually lie at the toe of scar.

(3)Multiple crest lines: tension cracks develop near the crest of large-scale landslides, making the ground sag, and causing multiple crest lines to develop in the area next to the cracks.

(4)Related sliding block: sliding blocks are observed between different scars, and the slope angles are usually not very steep.

(5)Landslide body: the vegetation in this area appears to be different from the surrounding areas, (e.g., lawn, bamboo forest), or forming a terrace. The upper part of the landslide body is a sagging terrain; main sliding body is presented as smooth angle and not too steep. The lower part of the body is as raised terrain. 
(6)Side cracks or erosion gullies: both sides of the landslide could be eroded by water due to the presence of landslide cracks. The two erosion side cracks could develop into gullies and incise toward the crest of the landslide, and eventually causing them to link together.

(7)Bulging or swelling at the toe area: the toe of the landslide becomes bulged due to squeezing of the sliding slope body. The toe sometimes locates on the erosion side of riverbanks and further scouring actions often trigger new slides.

Figure 10. Shading map of KSDF007 debris flow torrent area in eight different aspects with azimuth of: $45^{\circ}, 90^{\circ}, 135^{\circ}, 180^{\circ}, 225^{\circ}, 270^{\circ}, 315^{\circ}$, and $360^{\circ}$, from left to right as well as up and down.

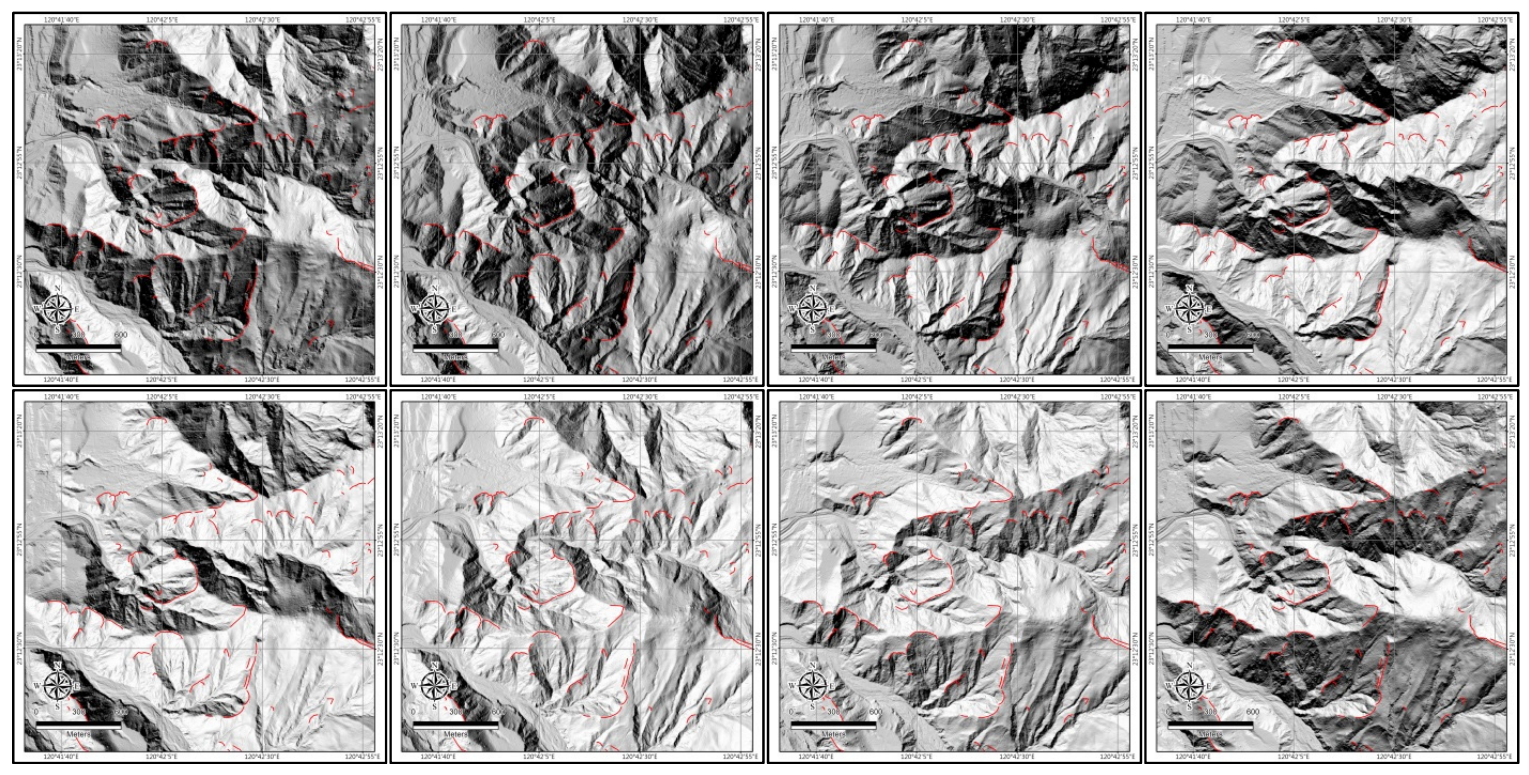

Figure 11. Results of identified scars in KSDF007 debris flow torrent area: (a) shading map with azimuth angle of $45^{\circ}$; (b) identified scars in the best aspect angle shading map.
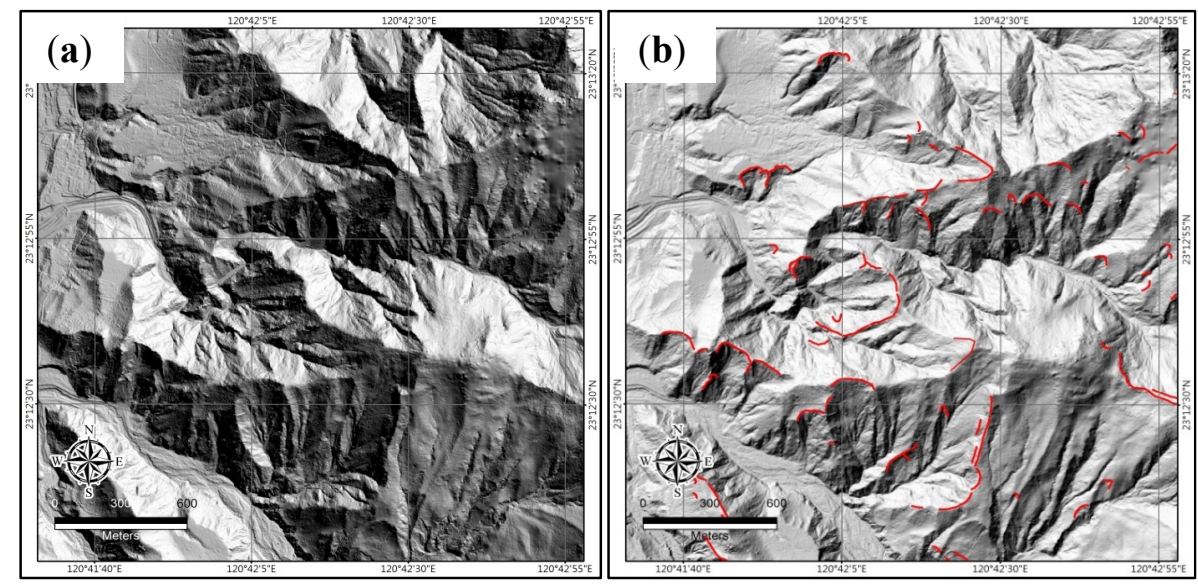

The mapping procedures start with using the shading map derived from Lidar data to locate the scars of landslide area, and then slope map is derived to identify the evidences of the large-scale landslide such as crown, landslide body, swelling toe, and scarp and digitized manually. Figure 12 is 
an example of an identified large-scale landslide and its features in the Maya area, Namasha study area. From the figure, we can identify some small landslides in the whole large-scale landslide area. For some of them, the erosion gullies and side cracks are well developed and can be easily recognized. There are many scars parallel to each other in the crown area. Figure 13 is the slope map of the same landslide area which enhances the topographic variations, and provides supporting evidence of landslide geomorphologic features. Comparisons of Figures 12 and 13 allow us to recognize features such as slag areas near the top of the swelling toe between two erosion gullies, and next to the scars on the crown. Combining the results illustrated in Figure 12 and 13, the large-scale landslide area is identified by markings made in red lines in Figure 13.

Figure 12. Example of identified large-scale landslides and their features in the Maya area of the Namasha study area.

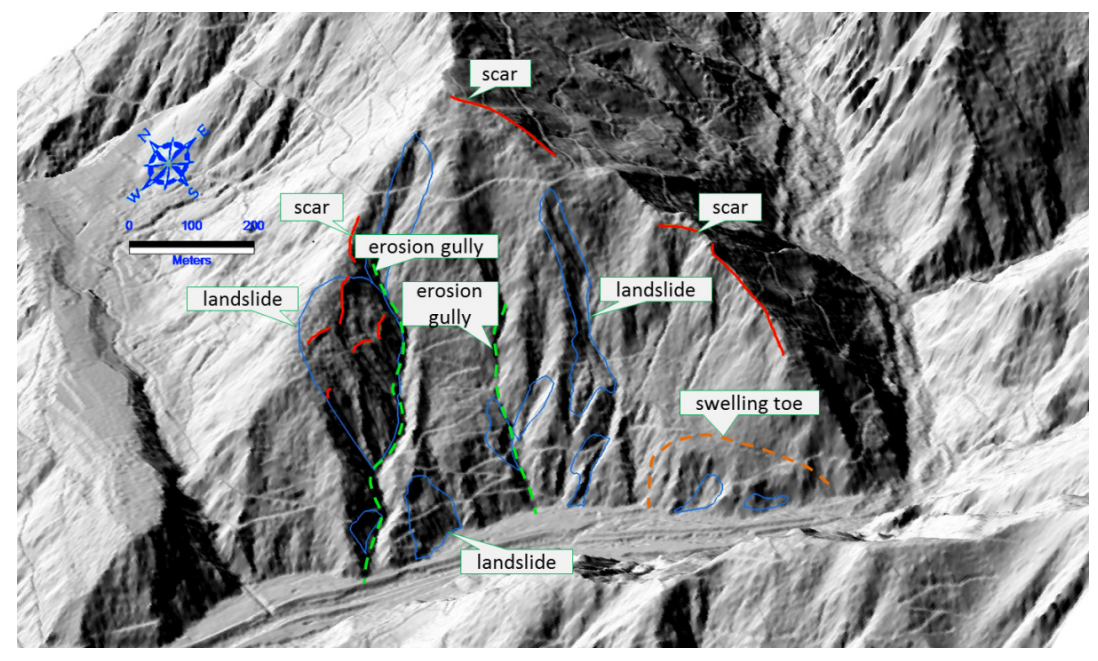

Figure 13. Example of the slope map of the large-scale landslide in the Maya area of the Namasha study area.

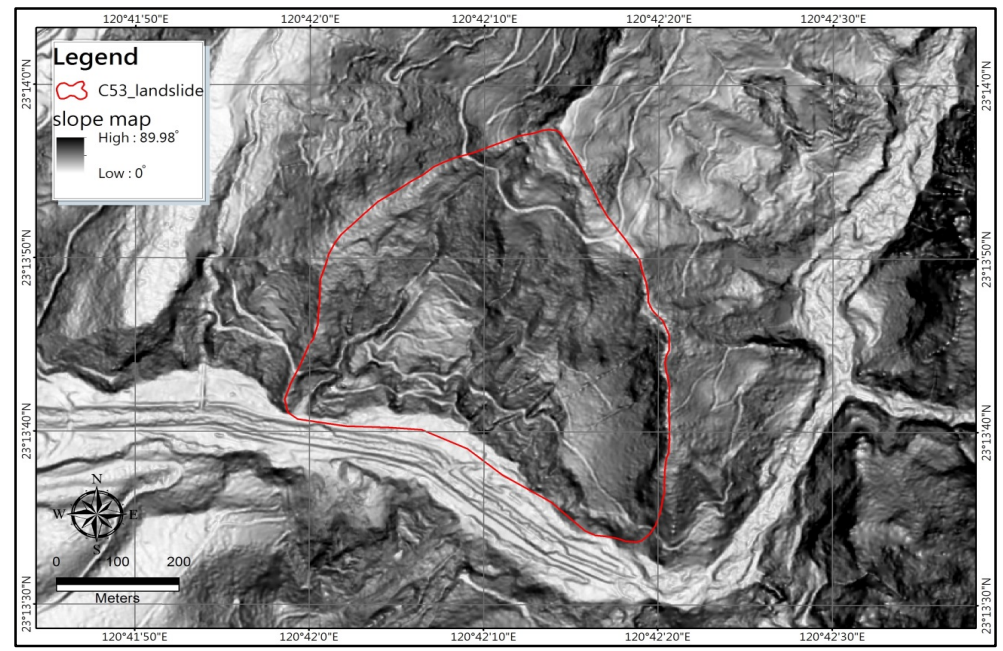

The methodological procedures for detecting large-scale landslide using Lidar data are proposed as: (1) Using a shading map derived from Lidar DEM to identify the scars/linear structures. (2) Using a 
slope map derived from Lidar DEM to help detecting the landslide geomorphologic features according to Varnes [10] and Varnes [11]. (3) By combining the results from the shading map and slope map, the potential large-scale landslide for types A, B, and C can be identified. The proposed procedures have been set up as discussed above and applied in the study areas.

\section{Comparisons of Landslide Investigation Methods Using Lidar Data and Aerial Photos}

\subsection{The Results of Landslide Identification using Aerial Photos}

The landslides distributions were mapped by comparing the aerial photos before and after Typhoon Morakot to find the exposed landslide scars and scarps. The landslides identified from the aerial photos after Typhoon Morakot and large-scale landslide distribution are shown in Figure 14. The total area affected by landslides is approximately 4,890 ha.

Figure 14. Distribution of identified landslides and large-scale landslide using aerial photos: (a) Namasha area, (b) Liuoguey area.

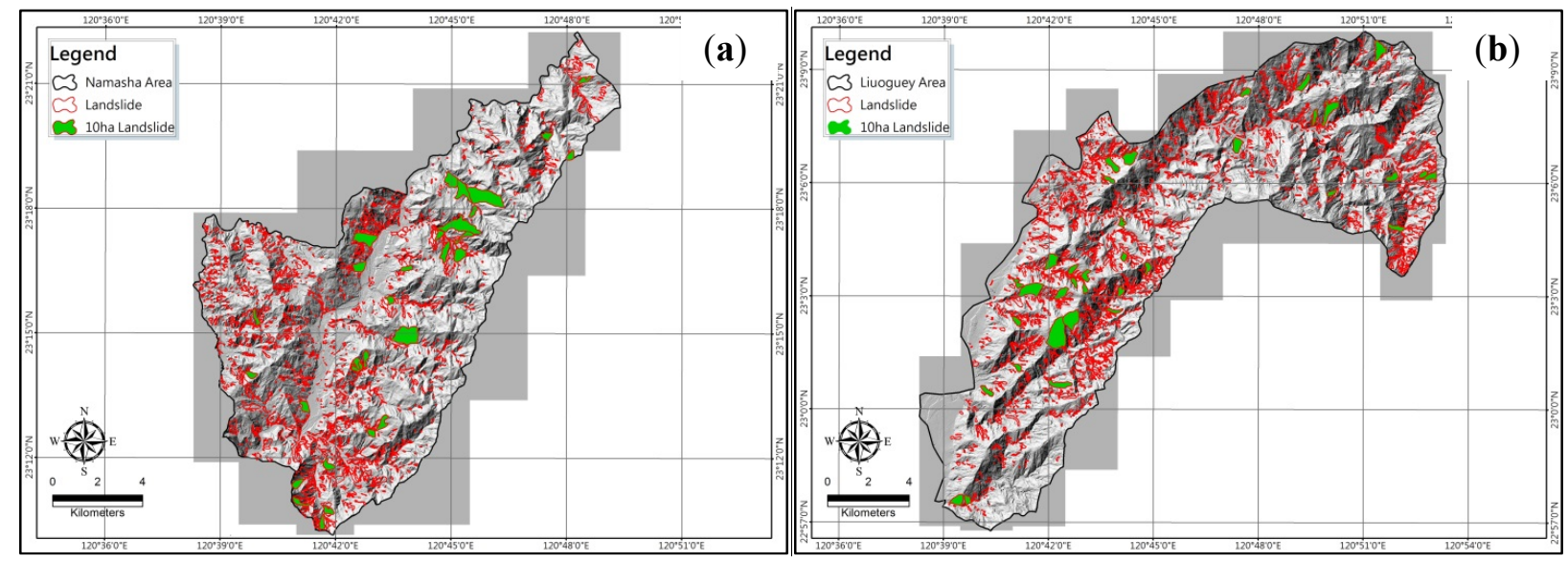

\subsection{Comparisons of Mapped Landslides using Lidar Information and Aerial Photos}

A comparison of the obtained results mapping large-scale landslides using Lidar and aerial photos has been carried out to verify the feasibility of identification procedures and reliability of results. The mapped landslides from aerial photos and landslide scars from Lidar data are plotted in Figure 15a for KSDF069 debris flow torrent basin area. From the figure, it is observed that the scars/linear structures identified using Lidar data are similar to the identified landslides from the aerial photo. However, some of the smaller landslides could not be identified through Lidar data, but most of the larger landslides are well identified. The type B landslides are prior event landslides with some vegetation recovery, which are identified by the Lidar information as shown in the upper-left part of the figure, but are not identified in the aerial photos. In addition, the aerial photos cannot be used to investigate the lower right section with cloud coverage, a limitation that is not present when using Lidar data due to the laser energy. Figure $15 \mathrm{~b}$ shows the landslides identified by aerial photos in comparison to the large-scale landslides mapped by Lidar. In the figure, most landslides identified in aerial photos are smaller and 
are often included in the mapped area of large-scale landslides. The total area of landslides mapped by aerial photo is 63 ha, and approximately $74 \%$ is included in the mapped large-scale landslide.

Figure 15. Comparisons of landslides mapped using Lidar information and aerial photos in KSDF069 debris flow torrent basin: (a) aerial photo with mapped landslide and scars by Lidar, (b) Lidar shading map with landslides from aerial photo and large-scale landslide.
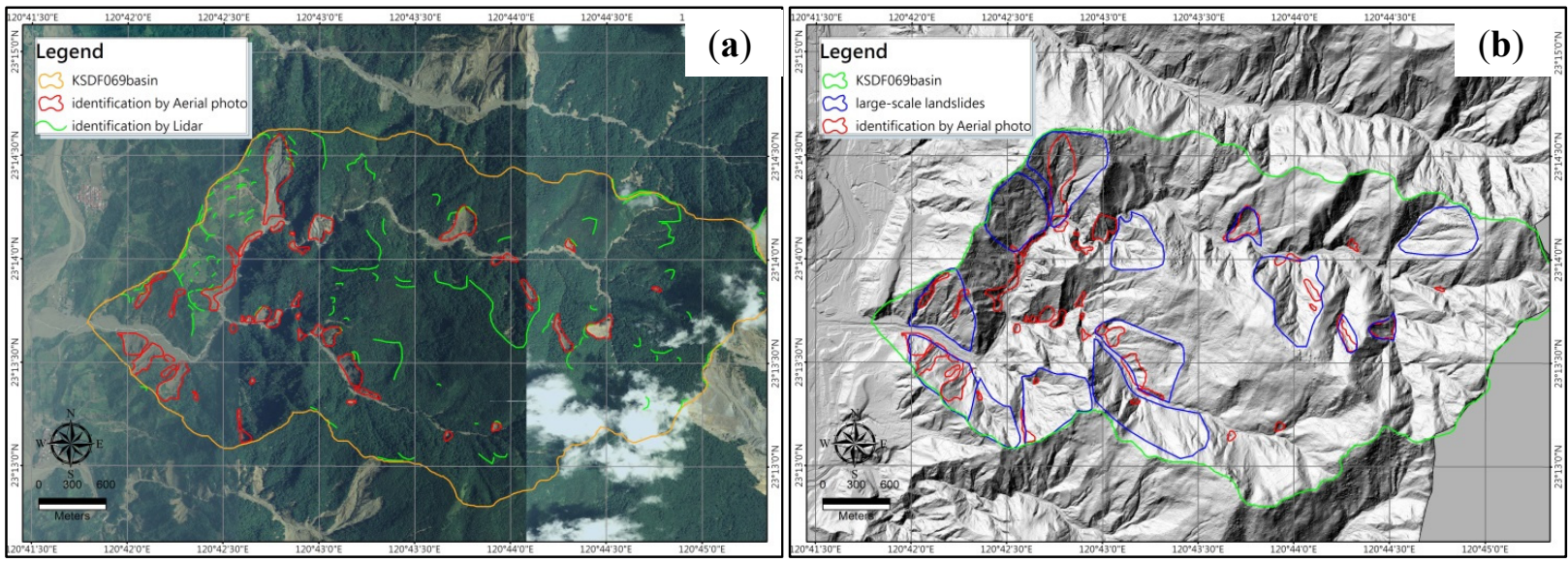

Figure 16. Comparisons of landslides mapped using Lidar information and aerial photos in KSDF007 debris flow torrent basin: (a) aerial photo with mapped landslides and scars by Lidar, (b) Lidar shading map with landslides from aerial photo and large-scale landslides
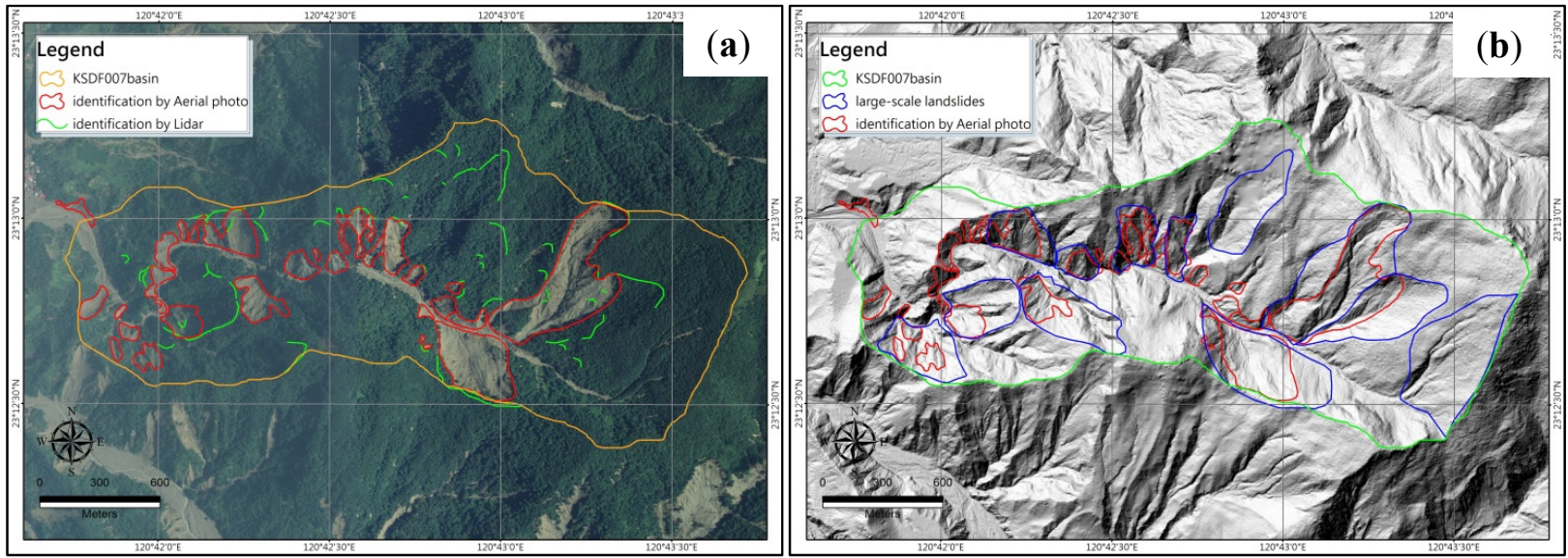

The mapped landslides from aerial photos and landslide scars from Lidar data are plotted in Figure 16a for KSDF007 debris flow torrent basin area. From the figure, it is observed that there are two large-scale landslides in the central right part of the map, which are identified well using both the aerial photos and Lidar methods. In the figure, 18 mapped landslides consist well using both methods, and 13 smaller landslides which lack identifiable linear structure cannot be detected using Lidar information, but can be identified by aerial photo. Figure $16 \mathrm{~b}$ shows the landslides identified by aerial photo in comparison to the large-scale landslides mapped by Lidar. The total area of landslide mapped by aerial photo is 60 ha and of which approximately $85 \%$ is included in the mapped large-scale landslides.

The identification of the large-scale landslides yield better results using the Lidar data to locate scars/linear structures as opposed to the use of the aerial photos, especially for type $\mathrm{B}$ and type $\mathrm{C}$ 
large-scale landslides. On the other hand, the Lidar data are less effective in the identification of smaller or shallow landslides because the ground variation features are not as significant. Thus, the procedures for application of Lidar information for identifying large-scale landslides appear to provide satisfactory results in the research area.

\section{Validation of Mapped Large-Scale landslides}

In order to validate the Lidar identification results, field investigation on the mapped large-scale landslides in the study area was conducted. It was found that the field evidences and topographic features were consistent with the mapped large-scale landslides using the Lidar technique. To further validate and examine the mapped results, two type A cases, No.A6 and No.A112 (assigned serial ID number for all the large-scale landslides in the study area), were selected for an additional detailed field investigation and stability analysis.

\subsection{An Overview of Large-Scale Landslides No.A6 \& A112}

The large-scale landslide A6 and A112 were both situated in the Namasha area, and both caused severe damage during typhoon Morakot, and thus were selected for additional detailed investigation and stability analysis. The topography and geology conditions of A6 and A112 are described below.

\subsubsection{The A6 Large-Scale Landslide}

The A6 landslide is a type A landslide triggered by Typhoon Morakot. The affected area is approximately 49.65 ha, with an average slope angle of $30.5^{\circ}$. The Formosa-2 satellite image (with a resolution of $2 \mathrm{~m}$ ) before Typhoon Morakot in 2008 and aerial photo after Typhoon Morakot are shown in Figure 17. Comparison of the images indicates that the large-scale landslide can be clearly observed, as can the widened and flooded river channel filled by debris. Part of the landslide body appears to have slid down-slope, causing it to be eroded by the channel flow. Large portions of the landslide mass remain on site, with potential to move further down-slope, making the A6 landslide a particular area of interest for further detailed study.

Figure 17. Remote sensing photos of A6 landslide: (a) Formosa-2 satellite image before Typhoon Morakot in 2008, and (b) aerial photo after Typhoon Morakot.
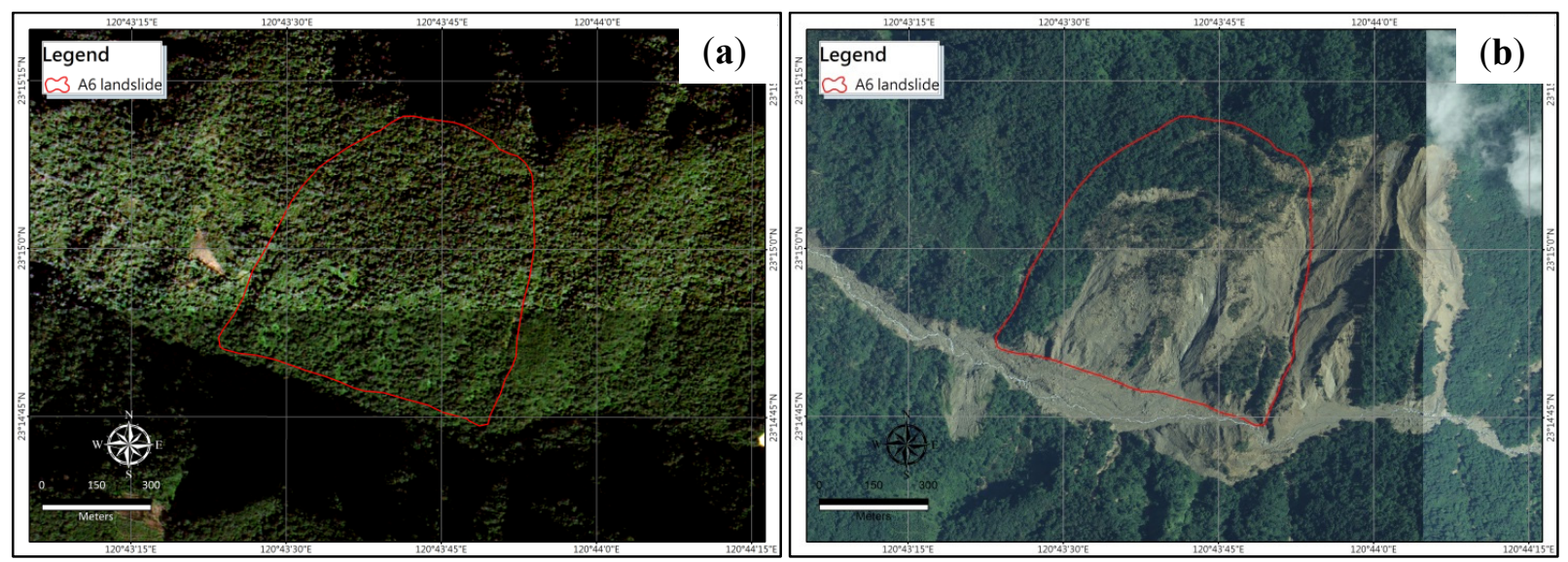
The geology and topographic conditions are illustrated in Figure 18. The main geological formation of the A6 landslide is the Changchikeng Formation [8], and the A-A' profile is the field investigation line. The formation is characterised by thin alternations of sandstone and shale. The altitude of the stratum is about $\mathrm{N} 80^{\circ} \mathrm{E}$ dipping $36^{\circ} \mathrm{E}$, and the angle formed between stratum and slope is approximately $20^{\circ}-30^{\circ}$.

Figure 18. Geological and topographic maps of the A6 landslide: (a) geological map, (b) Lidar topographic map.
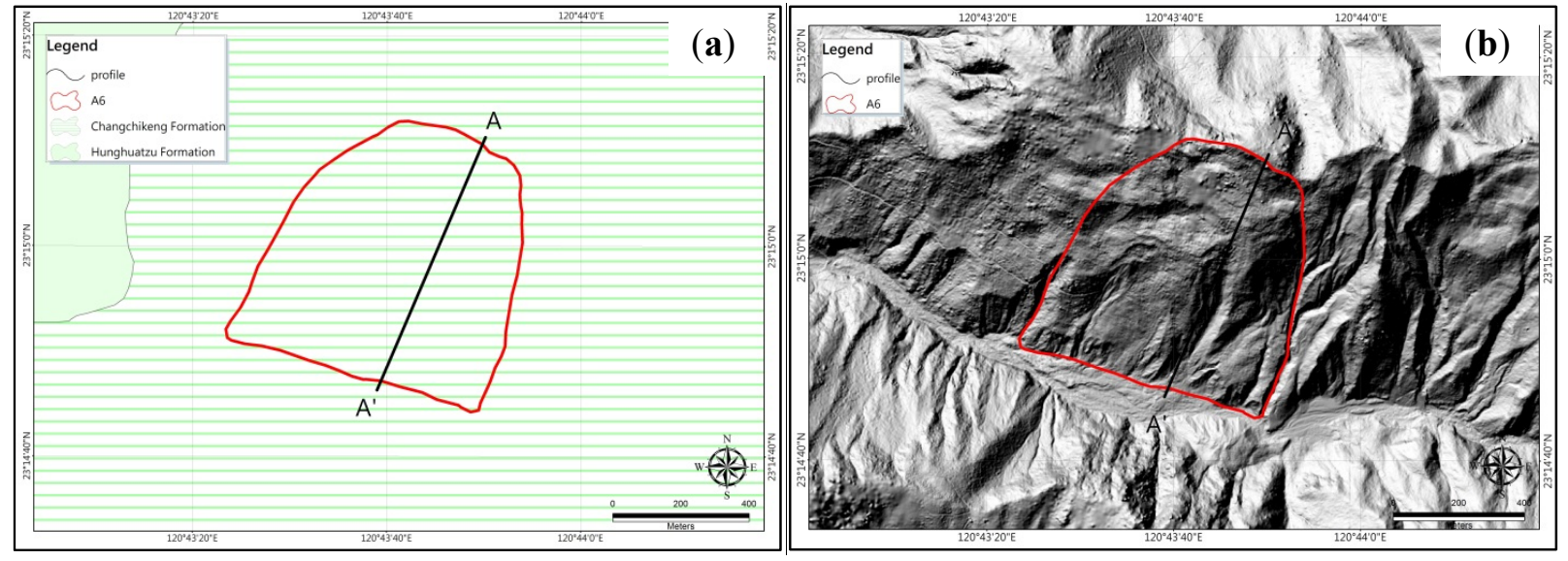

\subsubsection{The A112 Large-Scale Landslide}

The A112 landslide is a type A landslide affecting an area of approximately 11.97 ha with an average slope angle of $38.7^{\circ}$. The aerial photos of the A112 landslide before and after Typhoon Morakot are presented in Figure 19. Comparisons of the images before and after Typhoon Morakot, allow for clear observation of the landslide with details of the widen river channel being filled with debris. The river channel next to the A112 landslide is KSDF083 debris flow torrent. The landslide materials appear to contribute to the debris flow, with other landslides in the KSDF083 basin also contributing to the widening of the river channel and triggering further debris flow.

Figure 19. Aerial photos of the A112 landslide: (a) before Typhoon Morakot, (b) after Typhoon Morakot.

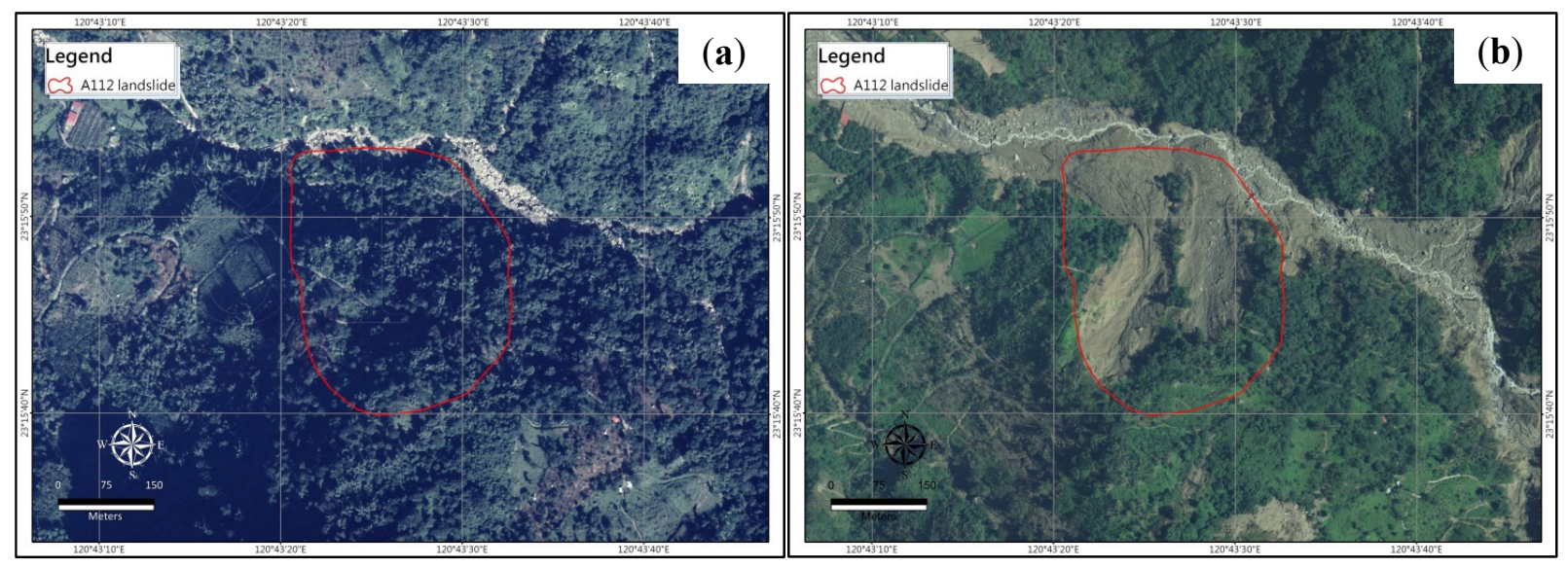


The geology and topographic conditions of the A112 landslide are illustrated in Figure 20. The main outcropping geological formations in the area are Sanming Shale and Hunghuatzu Formation [8], as illustrated in Figure 20a, with the B-B' profile as the field investigation line. They are characterized by an alternation of thick siltstone $(>2 \mathrm{~m})$ and thick shale $(>2 \mathrm{~m})$. The strike of the stratum is $\mathrm{N} 15^{\circ} \mathrm{E}$, dipping $45^{\circ} \mathrm{E}$, and the angle between the stratum and slope is approximately $70^{\circ}-80^{\circ}$. Figure $20 \mathrm{~b}$ is the Lidar DEM shading map of A112.

Figure 20. Geological and topographic maps of the A112 landslide: (a) geological map, (b) Lidar topographic map.
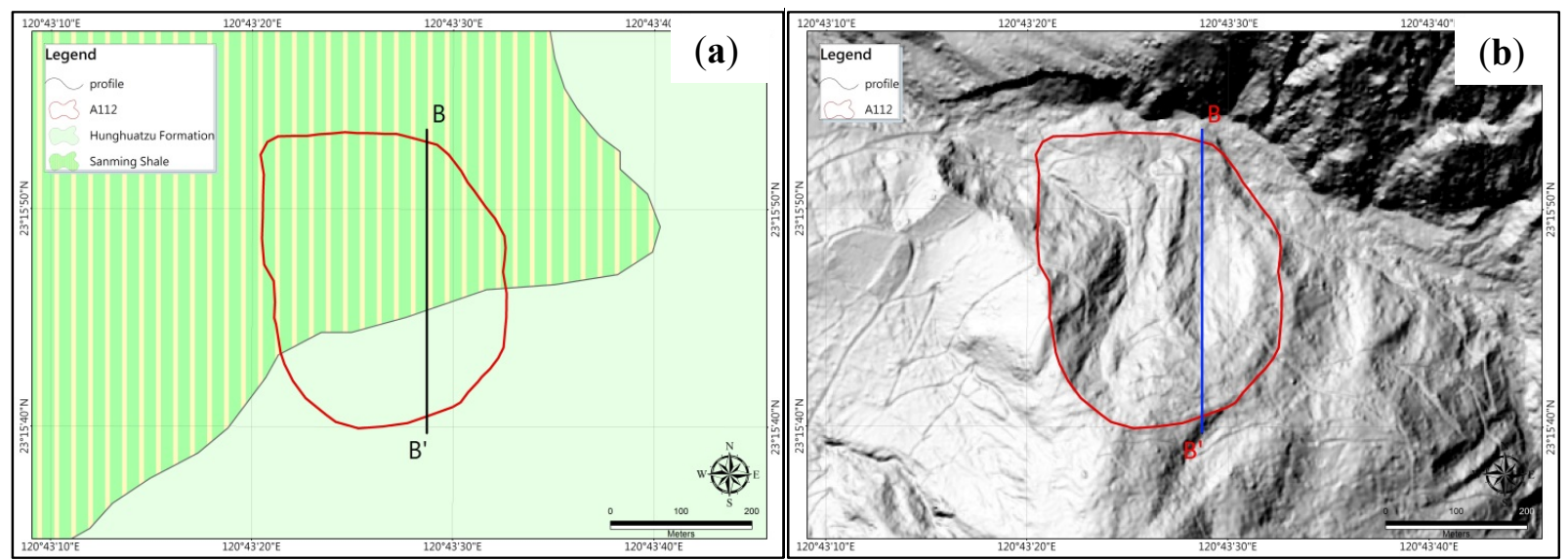

\subsection{Field Investigations and Stability Analysis of the A6 and A112 Large-Scale Landslides}

Detailed field investigations were conducted for the A6 and A112 large-scale landslides in order to verify the consistency of linear structures identified using Lidar data and field conditions. The scars and other relevant geomorphological features, as well as the landslide areas, were mapped and compared to the mapped results of Lidar information. The stability analyses were conducted to provide estimation of the failure condition, and location of the critical sliding surface was compared to the profile variations of the analyzed slope to provide validation and limitations of the large-scale landslides identified from Lidar information. The back analysis was performed by adjusting the material properties and ground water table to simulate the field conditions, and a commercially available program STABL was used. The location of the most critical sliding surface was determined by locating the most probable failure condition where the factor of safety would approach one. The initial values of material properties were estimated from database of the similar geological formation based on the Taiwan Engineering Geology Classification, and were gradually reduced during the back analysis until reaching reasonable failure condition.

\subsubsection{Field Investigation and Stability Analysis of the A6 Large-Scale Landslide}

Field investigation was conducted for the A6 landslide with the sliding depth in field estimating more than $10 \mathrm{~m}$. The landslide involved thin alternations of sandstone and shale, with shear zone containing black clay discovered near the estimated sliding surface. Layers of sandstone at the toe of the landslide were buckled. The dipping angle of the sandstone was 36 degrees with some cracks observed in the 
buckled layers. A schematic cross-section along profile A-A' is illustrated in Figure 21. The upper layer is colluvium and the lower one is bedrock in the Changchikeng Formation [8].

Comparisons between field investigation and Lidar identification results of A6 landslide are illustrated in Figure 22. The green lines in the figure mark the scars/linear structures identified using Lidar, whereas the yellow points represent the field investigation sites. Figures 22a through Figure 22d are photos of the corresponding sites, showing their respective field conditions. Figure 22a shows that the landslide mainly involved colluvium with grain sizes of 10-60 cm. In Figure 22b, the boundary of the A6 landslide is an erosion gully at the site, with the source area as a small scarp, which is consistent with a linear structure mapped for the small landslide. Figure $22 \mathrm{c}$ shows the colluvium above the exposed landslide surface which is located at a depth of more than $10 \mathrm{~m}$. Figure $22 \mathrm{~d}$ shows the exposed bedrock and the buckled structure. Due to the field condition, the crown of the A6 large-scale landslide could not be reached, but the results of field investigation fit with the Lidar identified scars and linear structures well, therefore proving the reliability of the mapped results completed by Lidar.

Figure 21. Schematic geological cross-section along profile A-A' of A6 landslide based on field investigation

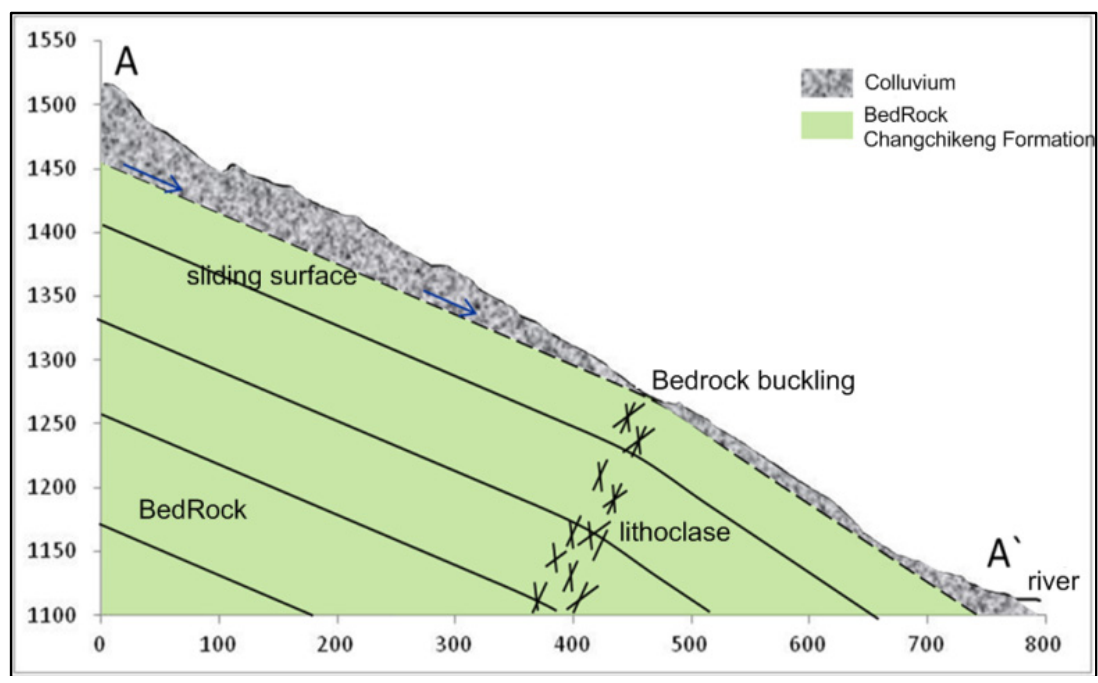

Stability analysis of the A6 landslide was conducted to verify the failure condition, and the location of the critical failure surface was compared to the slope profile variation after the Typhoon Morakot. The geotechnical parameters were referred to data of similar geological formations (Lin et al. [13]), and after back analysis, the parameters used were: unit weight of $23.5 \mathrm{kN} / \mathrm{m}^{3}$, ground water table reached the top of available gullies and near the ground surface, cohesion of $50 \mathrm{kPa}$, and a friction angle of 26 degrees. The corresponding safety factor with these parameters was 0.98 . The resulting critical sliding surface is plotted against the slope profiles before and after Typhoon Morakot in Figure 23. The differences between the original slope profile and profile after Typhoon Morakot provide information on the locations of head scarp, scars of possible sliding surface, and bulging or deposition near down-slope. The critical sliding surface determined from the back analysis fits the location of linear structure/scars and the topographic variations well at the crest and toe as shown in Figure 23. The head scarp of the critical sliding surface is located in close proximity to the edge of the 
slope and matches the scarp of the profile after Typhoon Morakot. The stability analysis provides cross validation of the mapped large-scale landslide, and the critical sliding surface can be used to check the possibility of failure occurrence and estimation of the landslide volume and amount of remaining unstable materials.

Figure 22. Comparisons between field investigation and Lidar identification results of A6 landslide-green lines mark the scars/linear structures by Lidar; yellow points represent the field investigation sites. (a) colluvium, (b) erosion gully, (c) depth of colluvium, (d) buckled structure.

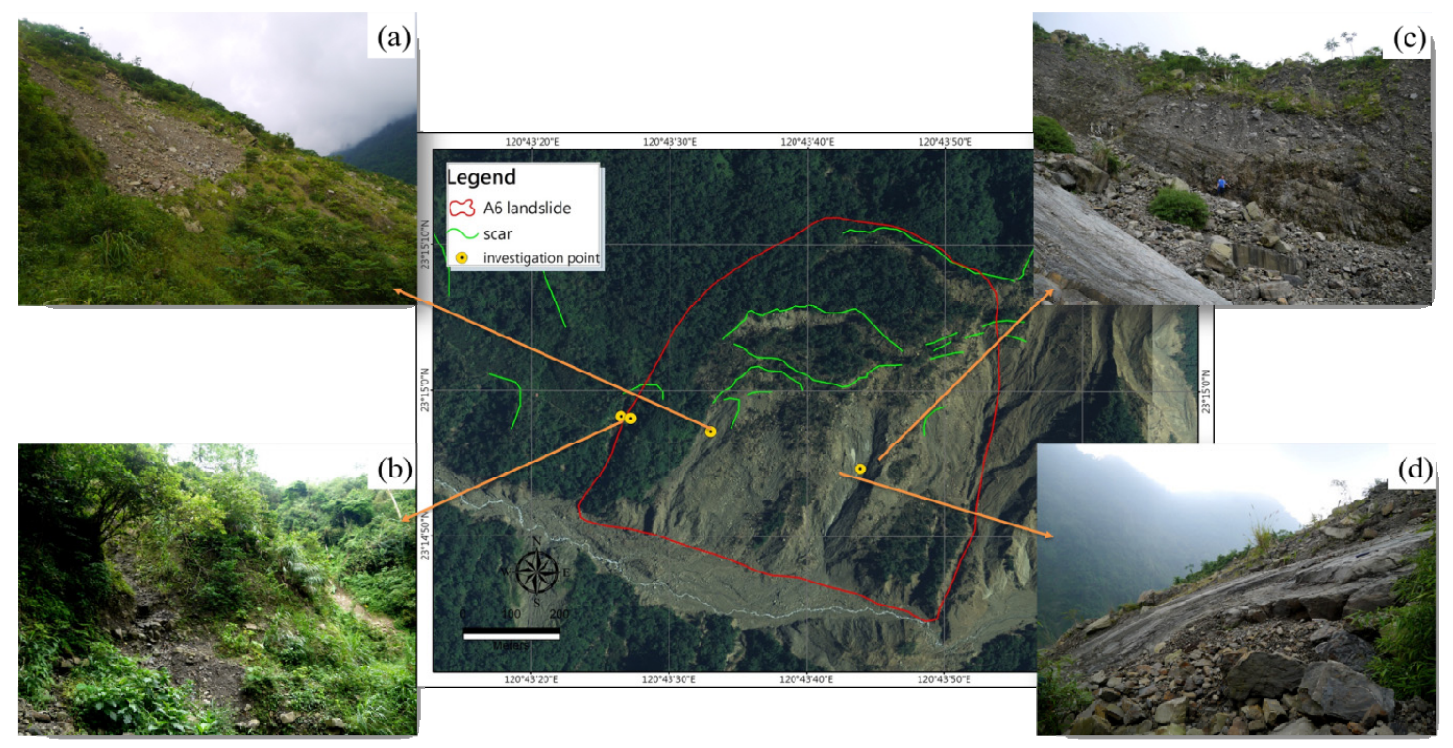

Figure 23. The critical sliding surface versus profiles showing before and after Typhoon Morakot of the A6 large-scale landslide.

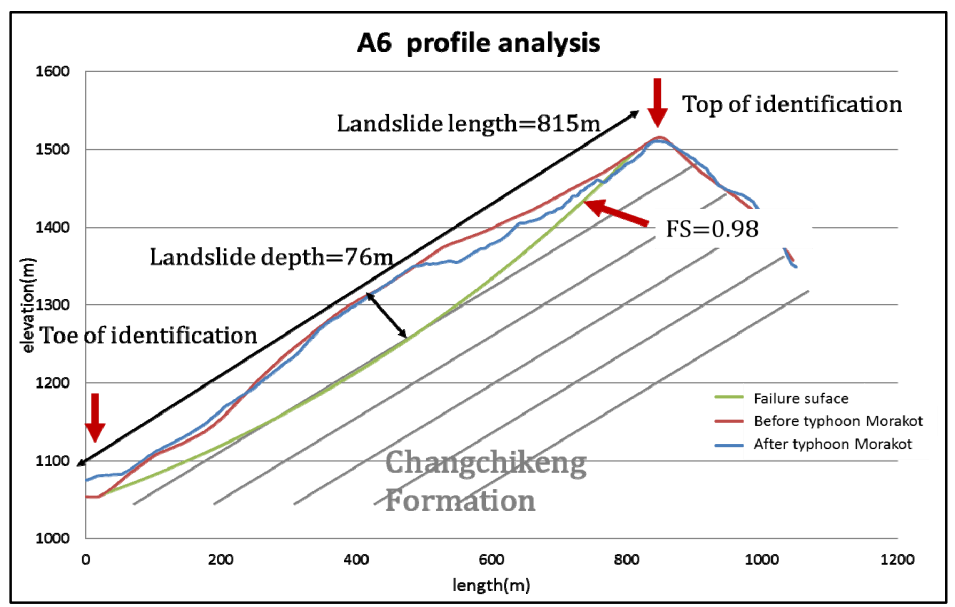

\subsubsection{Field Investigation and Stability Analysis of the A112 Large-Scale Landslide}

Field investigation was conducted for the A112 landslide where the sliding depth estimated in field was between 15 and $20 \mathrm{~m}$. The Hunghuatzu syncline was at a distance of 1,500 $\mathrm{m}$ from the landslide [8], 
and a small reverse fault across the river to the north of the A112 landslide could be detected. The landslide involved a thick colluvium layer, and a shear zone containing black clay was also observed near the estimated sliding surface. A $5 \mathrm{~m}$ wide fracture and $1.5 \mathrm{~m}$ high head scarp was observed near the crest of the estimated sliding surface. The cross-section along the profile B-B' is illustrated in Figure 24. The upper layer is represented by colluvium and the lower layer is bedrock in Hunghuatzu Formation and Sanming Shale [8].

Figure 24. Schematic geological cross-section along the profile B-B' of A112 landslide based on field investigation.

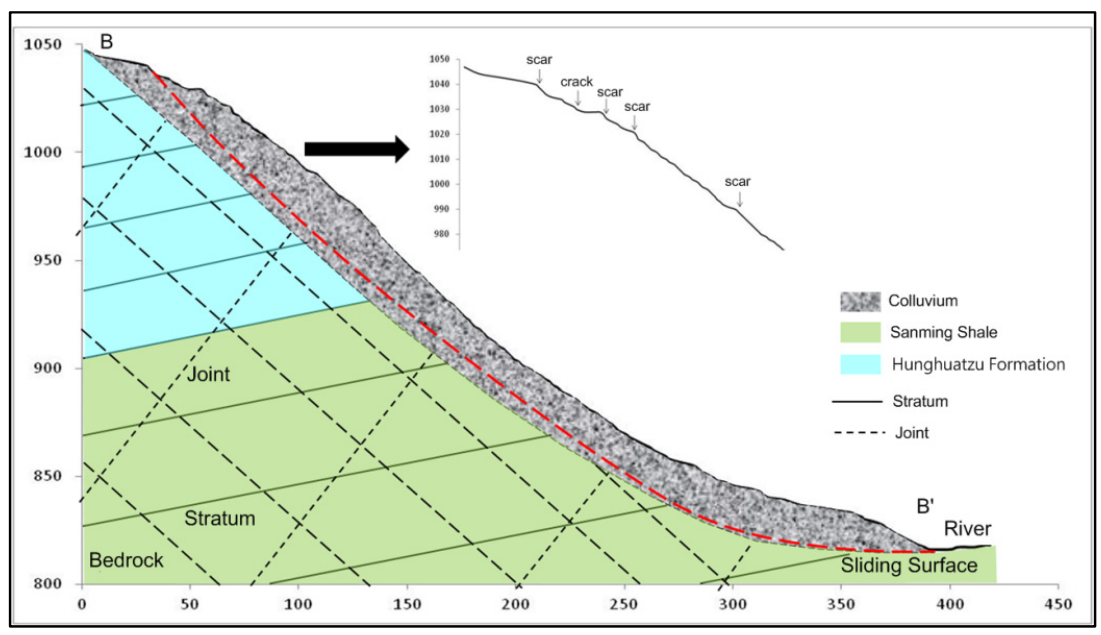

Figure 25. Comparisons between field investigations and Lidar identification results of A112 landslide; green lines mark the scars/linear structures by Lidar; yellow points represent the field investigation sites. (a) deposition in river, (b) landslide scars, (c) depth of head scarp, (d) shear zone, (e)black clay , (f) possible scars.

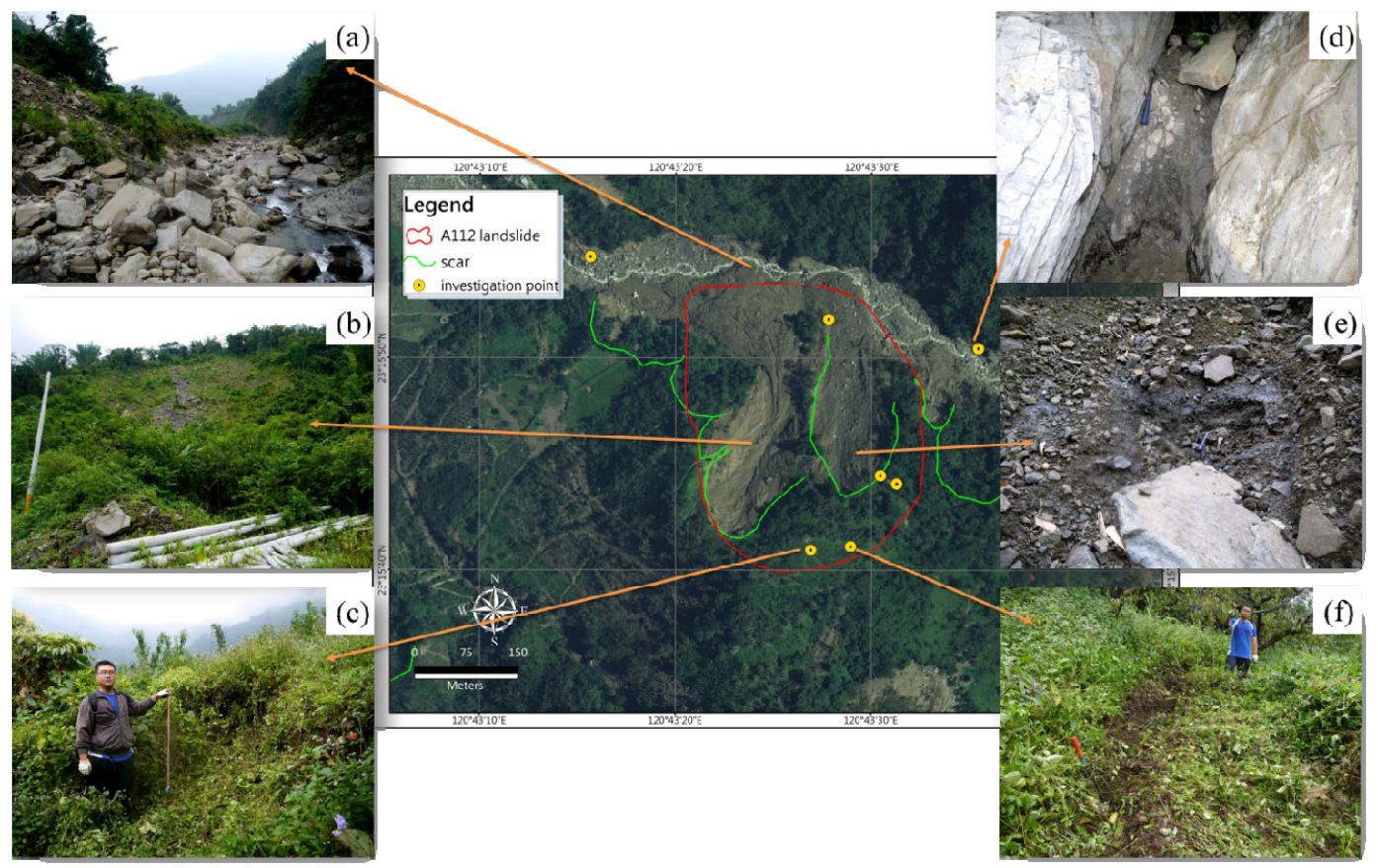


Comparisons between field investigation and Lidar identification results of A112 landslide are illustrated in Figure 25. The green lines in the figure mark the scars/linear structures identified using Lidar, and the yellow points represent the field investigation sites. The landslide mass was deposited into the river, causing the huge volume of debris to over-flood the riverbed as shown in Figure 25a. If a large amount of debris moves down-slope, it could result in damming of the river and cause further damage. In Figure 25b, cracks near the edge of the slope that are consistent with the scars/linear structures identified using Lidar data, are illustrated. Figure 25c shows a $1.5 \mathrm{~m}$ high head scarp near the edge of the slope which was not identified through use of Lidar data. A small reverse fault across the river beside the A112 landslide was observed in the field. A shear zone with black clay and signs of high groundwater, as shown in Figure 25d, were also observed. Figure 25e shows part of the sliding surface and bedrock with black clay found in the shear zone. Figure $25 \mathrm{f}$ shows landslide scars found in the field, but not identified by the Lidar data. A crack measuring $5 \mathrm{~m}$ wide was found near the crest, and the surrounding trees were found to be leaning in a direction suggesting a sliding motion had occurred. The range of identified large-scale landslides is represented by the red line in Figure 25.

Figure 26. The critical sliding surface versus profiles before and after Typhoon Morakot of the A112 large-scale landslide.

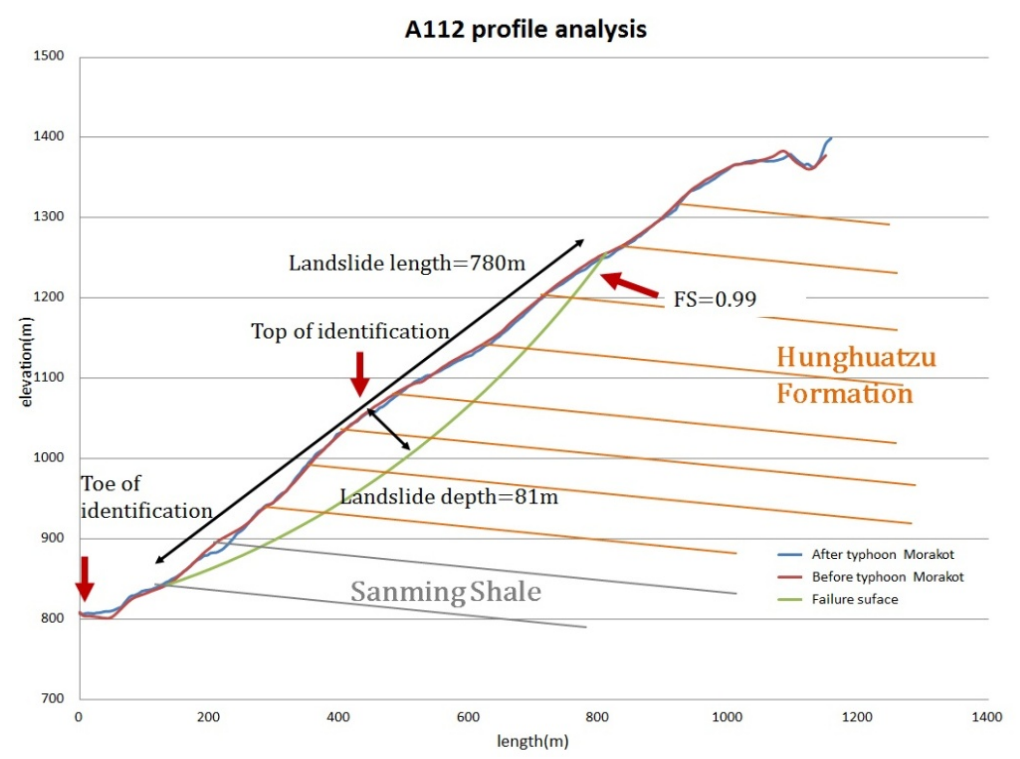

Back analysis of the stability of the A112 landslide was conducted to verify its failure condition in a similar fashion to the back analysis conducted for the A6 landslide. The parameters used in the back analysis were: unit weight of $23.5 \mathrm{kN} / \mathrm{m}^{3}$, ground water table reached the top of available gullies and near the ground surface, cohesion of $40 \mathrm{kPa}$, and friction angle of 28 degrees. The corresponding safety factor based on the parameters set above was 0.99 . The resulting critical sliding surface can be observed as fitting quite well with the topographic variations of slope profiles when plotted against the slope profiles before and after Typhoon Morakot in Figure 26. However, the critical sliding surface appears to extend beyond the landslide identified by Lidar, which can be seen clearly by mapping the critical sliding surface with the yellow profile on the aerial photo and shading map in Figure 27 . The aerial photo and Lidar shading map were re-examined leading to the discovery of another crack/linear 
structure to the south of the original map A112 landslide area. The comparison between the original mapped landslide (red line) and new data have been carried out, and a revised possible landslide scar has been drawn to incorporate the new data as illustrated in Figure 27. Figure 27a represents the aerial photo of the A112 landslide after Typhoon Morakot, in which the yellow dotted line delineates the new possible landslide area, and a small linear structure at the southern border and near the left fringe coincides with the remapped landslide. In Figure 27b, the linear structures near the crown and right fringe of the remapped landslide in the Lidar shading map become more obvious and appears to be evidence of retrogressive development of the originally mapped landslide. Thus, the stability analysis provides cross validation of the mapped large-scale landslide and the critical sliding surface, allowing for the possibility of checking a potential failure occurring, which supports the identification of the possible landslide.

Figure 27. Comparisons of the profile of the most critical sliding surface (yellow dotted line) of A112 landslide with: (a) aerial photo map, (b) Lidar shading map.
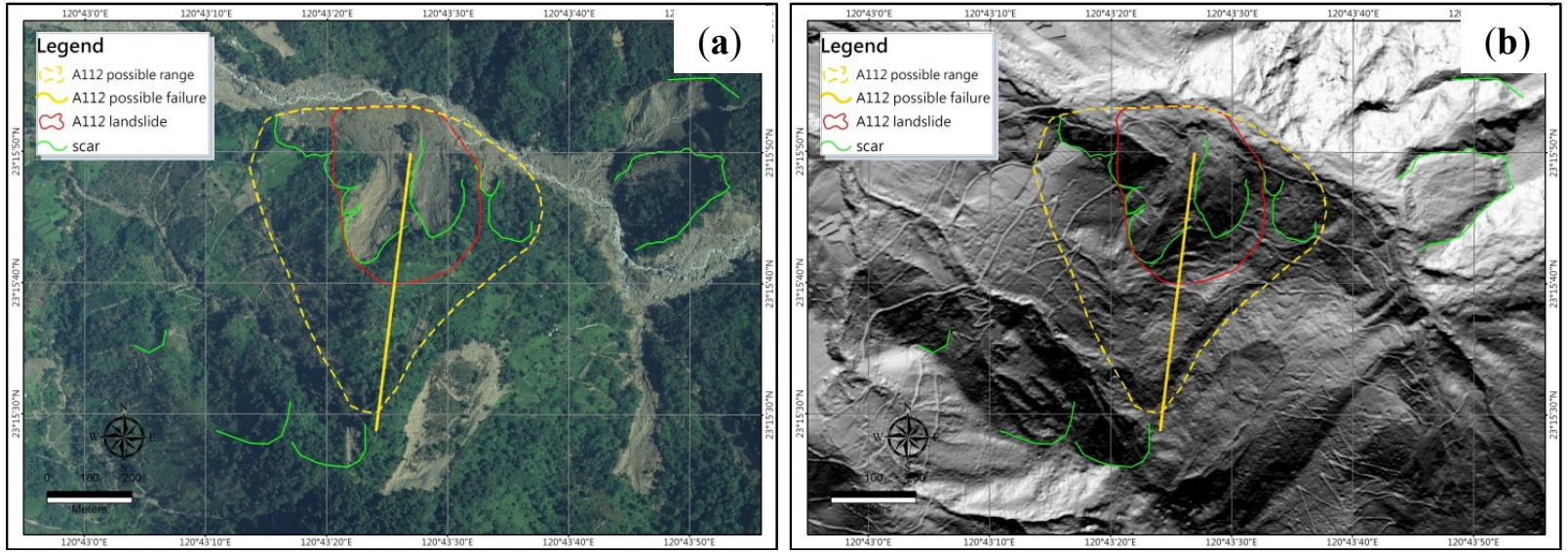

\section{Conclusions}

Since large-scale landslides often cause severe damage to lives and properties, it is desirable to identify and map them out for hazard mitigation purposes. In this paper, a methodological approach for identifying the large-scale landslides using the Lidar data was presented. Comparisons and validations were made using aerial photos. Field investigations were also conducted to validate the mapped large-scale landslides. Due to the high geomorphologic resolution, Lidar data proved to be very helpful in identifying the scars/linear structures associated with large-scale landslide in comparison to using aerial photos, especially for the vegetated sites. On the other hand, the Lidar data were not very effective in identifying the smaller or shallower landslides because the ground variation features were not as significant. Although the mapped results of Lidar were consistent with the field investigations, some scars and cracks found near the site were still not identified by Lidar. Thus, the detailed field investigation is helpful for validation and supplementing the Lidar identification of regional large-scale landslides. The procedures of application of Lidar information used in this study for identifying large-scale landslides appear to provide satisfactory results.

In addition to the Lidar technique, the stability analysis applied in this study proved to be effective for cross validation of the mapped large-scale landslide. Additionally, the study found that the critical 
sliding surface could be used to check the possibility of a failure occurring by pinpointing the location of the sliding surface and head scarp. In cases where the geomorphologic features were not fully developed, the stability analysis helped to provide a helpful tool for identifying the most critical conditions and the actual extent landslides. Therefore, when mapping the regional large-scale landslides using Lidar information, the additional use of supplemental data and tools, including aerial photos, field investigations, and stability analyses are also very helpful for validation and improvement of the overall identification results.

\section{Acknowledgments}

This research was supported by the Soil and Water Conservation Bureau (SWCB), Council of Agriculture, Executive Yuan, Taiwan, project number: SWCB-101-104. The authors would like to express their appreciation for the anonymous reviewers and editor, whose comments have helped to improve the overall quality of this paper.

\section{Conflicts of Interest}

The authors declare no conflict of interest.

\section{References}

1. Chigira, M. The Potential Area of Large-Scale Landslides (In Chinese); Scientific \& Technical Publishing Co., Ltd: Taipei, Taiwan, 2011.

2. Lin, M.L.; Wang, K.L.; Chen, S.C.; Feng, Z.Y.; Chang, K.T. Typhoon Morakot Major Hazard Investigation Project: Sub-Project(2), Major Landslide Hazard Investigation (Choshui River and Chishan River Basins) (In Chinese); National Science and Technology Center for Disaster Reduction: Taipei, Taiwan, 2009.

3. Schulz, W.H. Landslides Mapped Using LIDAR Imagery; US Geological Survey Open-File Report 2004-1396; US Department of the Interior, US Geological Survey: Seattle, WA, USA, 2004.

4. Schulz, W.H. Landslide Susceptibility Estimated From Mapping Using Light Detection and Ranging (LIDAR) Imagery and Historical Landslide Records; Open-File Report 2005-1405; US Department of the Interior, US Geological Survey: Seattle, WA, USA, 2005.

5. Miner, A.S.; Flentje, P.; Mazengarb, C.; Windle, D.J. Landslide Recognition using LiDAR derived Digital Elevation Models-Lessons Learnt from Selected Australian Example. In Proceedings of 11th IAEG Congress of the International Association of Engineering Geology and the Environment, Auckland, New Zealand, 5-10 September 2010; pp.5-9.

6. Lin, M.L.; Wang, K.L.; Chen, T.C.; Lin, S.C. Case study of severe debris flow hazard caused by typhoon Morakot (In Chinese). Sino-Geotechnics 2009, 122, 123-132.

7. Shao, P.H.; Kao, M.C., Geologic Map of Taiwan Scale 1:50,000 (Zhongpu) (In Chinese); Central Geological Survey, MOEA: Taipei, Taiwan, 2009.

8. Sung, Q.C.; Lin, C.W.; Lin, W.H.; Lin, W.C. Geologic Map of Taiwan Scale 1:50,000 (Jiaxian) (In Chinese); Central Geological Survey, MOEA: Taipei, Taiwan, 2000. 
9. Ho, C.S. Introduction to the Geology of Taiwan Explanatory Text of the Geologic Map of Taiwan (In Chinese); Central Geological Survey, MOEA: Taipei, Taiwan, 1986.

10. Varnes, D.J. Landslide Types and Processes. In Landslides and Engineering Practice; Highway Research Board Special Report 29; National Research Council (US): Washington, DC, USA, 1958; pp 20-47.

11. Varnes, D.J. Slope Movement Types and Processes. In Landslides: Analysis and Control; Transportation Research Board: Washington, DC, USA, 1978; pp. 11-33.

12. Foundation, N.R.D. Deep-Seated Landslide Susceptibility Analysis in Reservoir Area (In Chinese); Water Resource Planning Institute, Water Resource Agency, MOEA: Taichung, Taiwan, 2011.

13. Lin, M.L.; Wang, K.L.; Liao, J.T.; Yu., B.S. Simulation and Monitoring in Areas Susceptible to Landslide Hazard (2/4) (In Chinese); Central Geological Survey, Ministry of Economics: Taipei, Taiwan, 2008.

(C) 2013 by the authors; licensee MDPI, Basel, Switzerland. This article is an open access article distributed under the terms and conditions of the Creative Commons Attribution license (http://creativecommons.org/licenses/by/3.0/). 